\title{
Recent advances in the dissection of drought-stress regulatory networks and strategies for development of drought-tolerant transgenic rice plants
}

\author{
Daisuke Todaka ${ }^{1}$, Kazuo Shinozaki ${ }^{2}$ and Kazuko Yamaguchi-Shinozaki ${ }^{1}$ * \\ ${ }^{1}$ Laboratory of Plant Molecular Physiology, Graduate School of Agricultural and Life Sciences, The University of Tokyo, Tokyo, Japan \\ ${ }^{2}$ RIKEN Center for Sustainable Resource Science, Yokohama, Japan
}

Edited by:

Seiichi Toki, National Institute of Agrobiological Sciences, Japan

\section{Reviewed by:}

Kemal Kazan, Commonwealth Scientific and Industrial Research Organization, Australia

Martha Magaretha O'Kennedy, Council for Scientific and Industrial Research, South Africa

\section{*Correspondence:}

Kazuko Yamaguchi-Shinozaki, Laboratory of Plant Molecular Physiology, Graduate School of Agricultural and Life Sciences, The University of Tokyo, Bunkyo-ku, Tokyo 113-8657, Japan

e-mail:akys@mail.ecc.u-tokyo.ac.jp
Advances have been made in the development of drought-tolerant transgenic plants, including cereals. Rice, one of the most important cereals, is considered to be a critical target for improving drought tolerance, as present-day rice cultivation requires large quantities of water and as drought-tolerant rice plants should be able to grow in small amounts of water. Numerous transgenic rice plants showing enhanced drought tolerance have been developed to date. Such genetically engineered plants have generally been developed using genes encoding proteins that control drought regulatory networks. These proteins include transcription factors, protein kinases, receptor-like kinases, enzymes related to osmoprotectant or plant hormone synthesis, and other regulatory or functional proteins. Of the drought-tolerant transgenic rice plants described in this review, approximately onethird show decreased plant height under non-stressed conditions or in response to abscisic acid treatment. In cereal crops, plant height is a very important agronomic trait directly affecting yield, although the improvement of lodging resistance should also be taken into consideration. Understanding the regulatory mechanisms of plant growth reduction under drought stress conditions holds promise for developing transgenic plants that produce high yields under drought stress conditions. Plant growth rates are reduced more rapidly than photosynthetic activity under drought conditions, implying that plants actively reduce growth in response to drought stress. In this review, we summarize studies on molecular regulatory networks involved in response to drought stress. In a separate section, we highlight progress in the development of transgenic drought-tolerant rice plants, with special attention paid to field trial investigations.

\section{Keywords: drought, stress signaling, stress tolerance, rice, transgenic engineering}

\section{INTRODUCTION}

Drought is inevitable. For example, the U.S. suffered an agricultural drought in 2012, in which a $12 \%$ decrease in corn production was recorded compared with the previous year (USDA, 2014). Because such decreases in crop production cause enormous economic disruption, demand for the development of drought-tolerant crops is increasing.

Rice (Oryza sativa L.) is one of the world's most important cereals, with production comparable to that of wheat. In 2013, rice and wheat were cultivated in 124 and 126 countries, respectively, with corresponding worldwide production of 745 and 713 million tons (FAOSTAT). Compared with other cereal crops such as maize and wheat, rice is sensitive to decreases in soil water content because rice cultivars have been historically grown under flood irrigation conditions where the soil matric potential is zero. As a consequence, large amounts of water are required for production of rice compared with other crops. Production of $1 \mathrm{~kg}$ of rice seed requires 3,000 to 5,000 L of water, with less than half that amount needed for 1-kg seed production in other crops such as maize or wheat (Singh et al., 2002). Improvement of water-use efficiency during rice production should thus contribute significantly to agricultural water conservation and deserves much attention. Rice cultivars showing normal or even increased yield under drought stress conditions are expected to be closely related to those with high water-use efficiency.

Transgenic engineering approaches in plants have opened the door to the development of new cultivars with improved drought tolerance. Progress has been made in the generation of transgenic drought-tolerant rice plants. In this review, we begin with an overview of abiotic stress signaling pathways coordinated by a wide range of regulatory proteins, including key factors for the development of transgenic drought-tolerant rice plants, and then describe advances in the development of transgenic drought-tolerant rice. We also discuss growth regulatory mechanisms operating under water deficit stress conditions. Special attention is paid to transgenic rice plants showing improved drought tolerance under field conditions.

\section{REGULATORY MECHANISMS OF RESPONSES TO ABIOTIC STRESSES, INCLUDING DROUGHT, IN Arabidopsis}

Abiotic stresses, such as drought, high salinity, and low temperature, induce the expression of a large number of genes. The 
induction of these genes under stress is regulated through complex transcriptional networks (Yamaguchi-Shinozaki and Shinozaki, 2006). The key genes functioning in these transcriptional networks have been revealed by molecular studies and are important candidates for the development of transgenic plants tolerant to abiotic stress. Here, we highlight two important pathways of transcriptional networks under abiotic stress conditions in Arabidopsis: an abscisic acid (ABA)-dependent signaling pathway and an ABA-independent regulatory network mediated by dehydration responsive element-binding (DREB)-type transcription factors (Figure 1A). Numerous excellent review articles on global abiotic stress regulatory networks have previously been published (Zhu, 2002; Bartels and Sunkar, 2005; Chinnusamy et al., 2007; Hua, 2009; Thomashow, 2010; Qin etal., 2011; Deinlein et al., 2014; Golldack et al., 2014; Yoshida et al., 2014).

\section{THE ABA-DEPENDENT SIGNALING PATHWAY}

In Arabidopsis, significant progress has been made in the elucidation of molecular mechanisms of transcriptional networks involved in abiotic stress response. The phytohormone ABA is a major molecule facilitating signal transduction during drought stress response. A key enzyme for ABA biosynthesis is 9-cisepoxycarotenoid dioxygenase (NCED; Iuchi et al., 2001). Among five genes encoding NCED in Arabidopsis, expression of NCED3 has been found to increase under water deficit conditions (Iuchi etal., 2001). A G-box recognition sequence located $-2,248$ bp from the NCED3 transcriptional start site has recently been shown to be important for this gene's expression under water deficit conditions (Behnam etal., 2013). It has also emerged that $\mathrm{ABA}$ intercellular transport mechanisms are important for ABA-dependent drought responses. Kuromori et al. (2014) have demonstrated that specific cells in vascular tissue synthesize ABA and transport the molecule to target cells. Bauer et al. (2013) have proposed that $\mathrm{ABA}$ is autonomously synthesized in guard cells.

Synthesized or transported ABA is perceived by a receptor complex, which consists of PYR (PYRABACTIN RESISTANCE)/PYL (PYR1-LIKE)/RCAR (REGULATORY COMPONENT OF ABA RESPONSE), PP2C (protein phosphatase 2C), and SnRK2 (sucrose non-fermenting 1-related protein kinase 2; Cutler et al., 2010; Raghavendra et al., 2010; Umezawa et al., 2010; Weiner et al., 2010). A suite of studies has clarified the molecular structural changes that occur during $\mathrm{ABA}$ perception and in the ABA signaling cascade (Cutler et al., 2010; Raghavendra et al., 2010; Umezawa et al., 2010; Weiner et al., 2010; Miyakawa et al., 2013). In the absence of ABA, PP2Cs repress the ABA signaling pathway by dephosphorylation-triggered inactivation of SnRK2s. In the presence of ABA, ABA-bound PYL/PYR/RCARs recognize and bind to PP2Cs, thereby releasing SnRK2s from PP2C-dependent negative regulation. The activated SnRKs phosphorylate downstream proteins including AREB/ABF (ABA-responsive cis-element binding protein/ABA-responsive cis-element binding factor) transcription factors. The AREB/ABF transcription factors have a bZIP domain and four conserved domains containing SnRK2 phosphorylation sites. The phosphorylated AREB/ABFs are activated and bind to the ABA-responsive cis-element (ABRE; PyACGTGG/TC), which is enriched in promoter regions of drought-inducible genes. $\mathrm{AREB} / \mathrm{ABF}$ function as master transcriptional activators regulating ABRE-dependent gene expression in ABA signaling under drought stress conditions.

\section{THE ABA-INDEPENDENT SIGNALING PATHWAY MEDIATED BY DREB2 AND DREB1/CBF}

Evidence has revealed that ABA-independent signaling pathways are also important in abiotic stress response. DREB2 proteins are members of the AP2/ERF family of plant-specific transcription factors. Among the eight DREB2 genes in Arabidopsis, DREB2A and $D R E B 2 B$ are highly induced by drought, high salinity, and heat stress, and function as transcriptional activators in the ABAindependent pathway. A negative regulatory domain has been identified in the DREB2A amino acid sequence and is reported to be involved in DREB2A protein stability (Sakuma et al., 2006a; Mizoi et al., 2012). Under non-stressed conditions, degradation of DREB2A proteins occurs via ubiquitination of DREB2A by the C3HC4 RING domain-containing proteins DRIP1 (DREB2Ainteracting protein1) and DRIP2 (Qin et al., 2008; Morimoto et al., 2013). Kim et al. (2012a) have proposed that DREB2A expression is repressed by GRF7, a growth-regulating factor, to prevent growth inhibition under non-stressed conditions. DREB2A also plays a role in high temperature stress response and increased heat stress tolerance (Sakuma et al., 2006b). The use of HsfA1 multiple mutants has revealed that DREB2A expression under heat stress conditions is regulated by HsfA1 (heat shock factor A1) proteins (Yoshida et al., 2011).

DREB1/CBF transcription factors are another subfamily that regulates expression of many abiotic stress-responsive genes. DREB1/CBFs are key regulators in low-temperature stressresponsive gene expression. Transgenic Arabidopsis plants overexpressing DREB1/CBF genes have been found to improve low-temperature stress tolerance as well as drought and salinity stress tolerance (Kasuga et al., 1999; Yamaguchi-Shinozaki and Shinozaki, 2006). Several studies have reported that expression of $D R E B 1 / C B F$ genes is directly or indirectly modulated by regulatory factors such as HOS1 (Dong etal., 2006), ICE1 (Chinnusamy etal., 2003), SIZ1 (Miura etal., 2007), MYB15 (Agarwal etal., 2006), PIF7 (Kidokoro etal., 2009), CAMTA3 (Doherty etal., 2009), and a clock component (Dong etal., 2011). Recent excellent reviews by Medina etal. (2011) and Mizoi et al. (2012) are highly informative regarding DREB transcription factor proteins and the related signaling cascade in Arabidopsis.

\section{MOLECULAR RESPONSES TO DROUGHT STRESS IN RICE}

In rice, more than 5,000 genes are up-regulated and more than 6,000 are down-regulated by drought stress (Maruyama et al., 2014). A comparison between rice and Arabidopsis by Maruyama et al. (2014) demonstrated that different metabolites are accumulated under abiotic stress conditions. For example, high expression levels of genes encoding isocitrate lyase and malate synthase in the glyoxylate cycle along with glucose accumulation under abiotic stress conditions were observed in rice, but not in Arabidopsis. Additionally, reduced expression of the cytochrome P450 735A gene was correlated with decreased cytokinin levels in rice, but not in Arabidopsis. Similar 
comprehensive analyses of drought stress-responsive genes, proteins, and metabolites in rice have been performed as follows. Wang etal. (2011a) identified 5,284 drought stress-responsive genes. Lenka et al. (2011) compared drought-responsive genes in indica rice genotypes having contrasting drought tolerances. Up-regulation of the $\alpha$-linolenic acid metabolic pathway was observed in the drought-tolerant genotype. Degenkolbe et al. (2009) also investigated comprehensive expression profiles of drought-responsive genes in both drought-sensitive and droughttolerant rice genotypes. They found that senescence-related degradation processes and expression of photosynthesis-related genes were reduced in drought-tolerant cultivars compared with those in drought-sensitive ones. Using the comprehensive expression data, the authors also identified marker transcripts for selection of drought tolerance in a range of rice germplasm resources through integrated analyses of gene expression and stress tolerance (Degenkolbe et al., 2013). The marker transcripts showed a significant correlation between expression level and tolerance under drought stress conditions. One of the markers was a gene for cytosolic fructose-1,6-bisphosphatase, an enzyme that catalyzes a highly regulated step in C-metabolism. Ray et al. (2011) have reported that genes responsive to drought stress conditions significantly overlap with those expressed during panicle and seed development. Shu et al. (2011) performed integrated analyses of two-dimensional electrophoresis - mass spectrometry - mass spectrometry, cDNA microarray, and gas chromatography - mass spectrometry data from rice seedlings after drought stress treatment to, respectively, determine protein expression levels, gene expression levels, and metabolite contents. The authors speculated that energy conversion from carbohydrates and/or fatty acids to amino acids increased under drought stress conditions. Epigenetic research on drought response in rice has been also reported. Wang et al. (2011b) examined drought-induced genome-wide DNA methylation and its association with drought tolerance. Zong et al. (2013) investigated the genome-wide distribution pattern of histone $\mathrm{H} 3$ lysine 4 tri-methylation and found that methylation levels were positively correlated with expression levels of some of the evaluated drought-responsive genes.

While these large data sets have provided much information on drought responses in rice, studies on associated signaling cascades have been limited. Evidence indicates that O. sativa NCED transcripts are up-regulated along with ABA accumulation under drought stress conditions (Maruyama et al., 2014), and that a core ABRE sequence in the promoter regions of drought-inducible genes is enriched in rice, Arabidopsis and soybean (Maruyama et al., 2012). These results suggest that the ABA-dependent signaling pathway in rice is activated by drought stress, similar to that of Arabidopsis and other plant species. He et al. (2014) determined the crystal structure of the ABA-OsPYL2-OsPP2C06 complex and suggested that the complex has the potential to be an ABA receptor in rice. Kim et al. (2012b) identified a rice ABA signaling unit composed of OsPYL/RCAR5, OsPP2C30, SAPK2, and OREB1 for ABA-dependent gene regulation. They have reported that OsPYL/RCAR5 functions as a positive regulator of abiotic stress-responsive gene expression and that transgenic rice plants overexpressing OsPYL/RCAR5 have improved drought tolerance. The OREB1 bZIP-type transcription factor, which is ortholog to Arabidopsis AREB, has been shown to regulate the ABA-dependent pathway in rice (Chae et al., 2007; Hong et al., 2011).

Experimental evidence has demonstrated that rice DREB transcription factors also function as important regulators in ABA-independent drought responses. The rice genome contains five DREB2-type genes, two of which-OsDREB2A and OsDREB2B - are up-regulated by abiotic stress (Matsukura et al., 2010). Transgenic rice plants overexpressing these two genes have been found to have increased drought tolerance (Chen et al., 2008; Cui et al., 2011). OsDREB2B generates two forms of the transcripts, OsDREB2B1 and OsDREB2B2. OsDREB2B1 encodes a non-functional protein (Short ORF in Figure 1B). OsDREB2B2 contains a coding region with AP2/ERF DNA binding domain (Long ORF in Figure 1B). OsDREB2B2 transcripts were accumulated by heat, cold, drought, and high salinity stress treatments, while OsDREB2B1 transcripts were not changed except for cold stress. These results suggest that OsDREB2B2 plays an important role in the abiotic stress response of rice through the alternative splicing regulatory system (Matsukura et al., 2010). Expression of $O s D R E B 1 A$ and $O s D R E B 1 B$ is up-regulated by low-temperature stress (Dubouzet et al., 2003), while expression of OsDREB1F and OsDREB1G is increased by water deficit stress (Chen et al., 2008; Wang et al., 2008). In contrast to other DREB1-type genes in rice, OsDREB1F likely participates as a regulatory factor in the ABAdependent pathway. Transgenic rice plants overexpressing these genes also exhibit increased drought tolerance. It has been reported that OsICE1, OsICE2, OsSIZ1, and OsSIZ2 are involved in the cold stress signaling pathway that regulates OsDREB1B expression (Park et al., 2010; Nakamura et al., 2011).

\section{TRANSGENIC RICE PLANTS THAT ENHANCE DROUGHT STRESS TOLERANCE}

Genetic engineering has opened the door to the development of new cultivars with improved drought stress tolerance. Reports on transgenic rice plants that show increased drought stress tolerance are accumulating. A selected list of transgenic rice plants, which includes information on transgenes and promoters used for the transformations as well as plant stress tolerance and growth performance, is given in Table 1.

\section{bZIP-TYPE TRANSCRIPTION FACTORS}

OsbZIP23, which is closely related to the Arabidopsis homologs $\mathrm{ABF} / \mathrm{AREB}$, is a major regulator of ABA-dependent pathways (Xiang et al., 2008). In the study of Xiang et al. (2008), OsbZIP23overexpressing rice plants showed increased sensitivity to ABA at both germination and post-germination stages. The transgenic plants also exhibited enhanced tolerance to drought and salinity stresses. A transactivation assay indicated that OsbZIP23 functions as a transcriptional activator, with two regions of the OsbZIP23 amino acid sequence-at N- (1-59) and C- (210-240) termini-important for transcriptional activation. Microarray analysis detected hundreds of downstream genes of OsbZIP23 with diverse functions. These downstream genes included genes encoding stress-related transcription factors, protein kinases, dehydrins, and LEA proteins. 


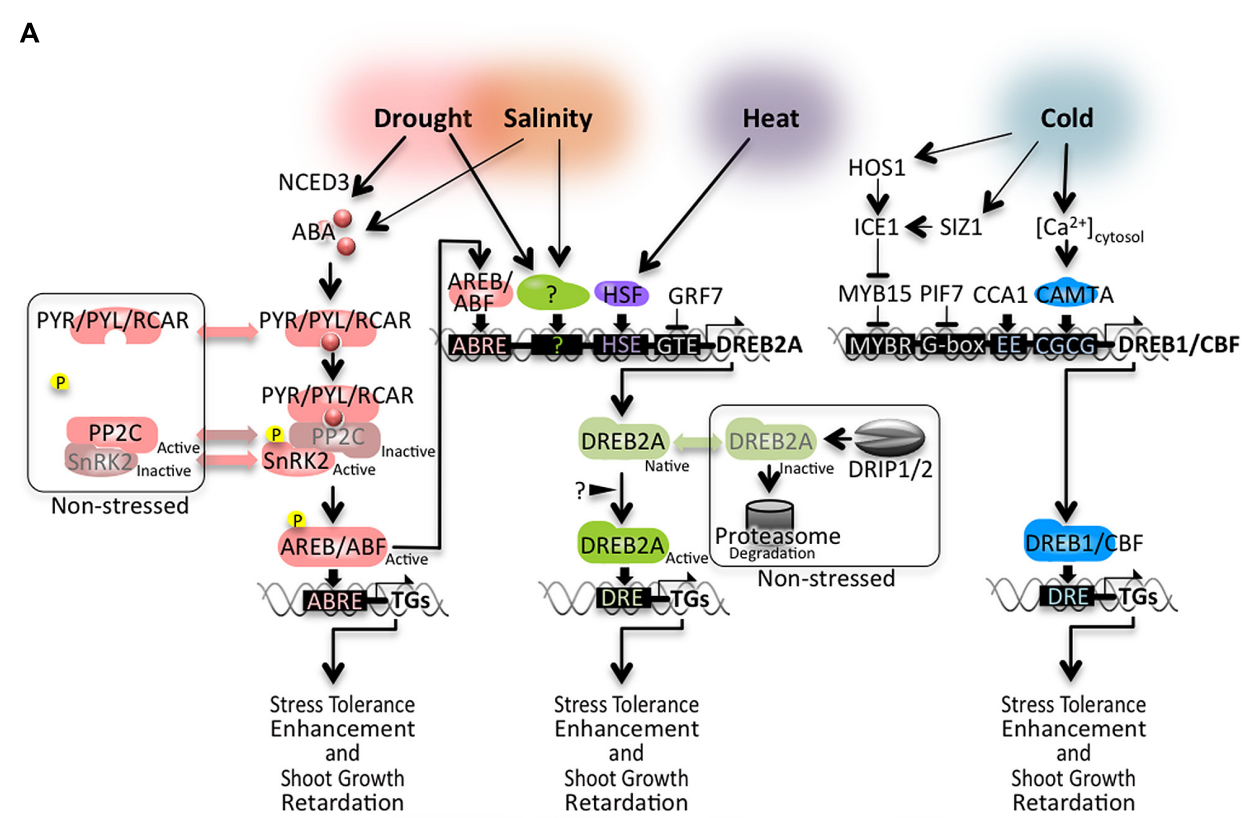

B

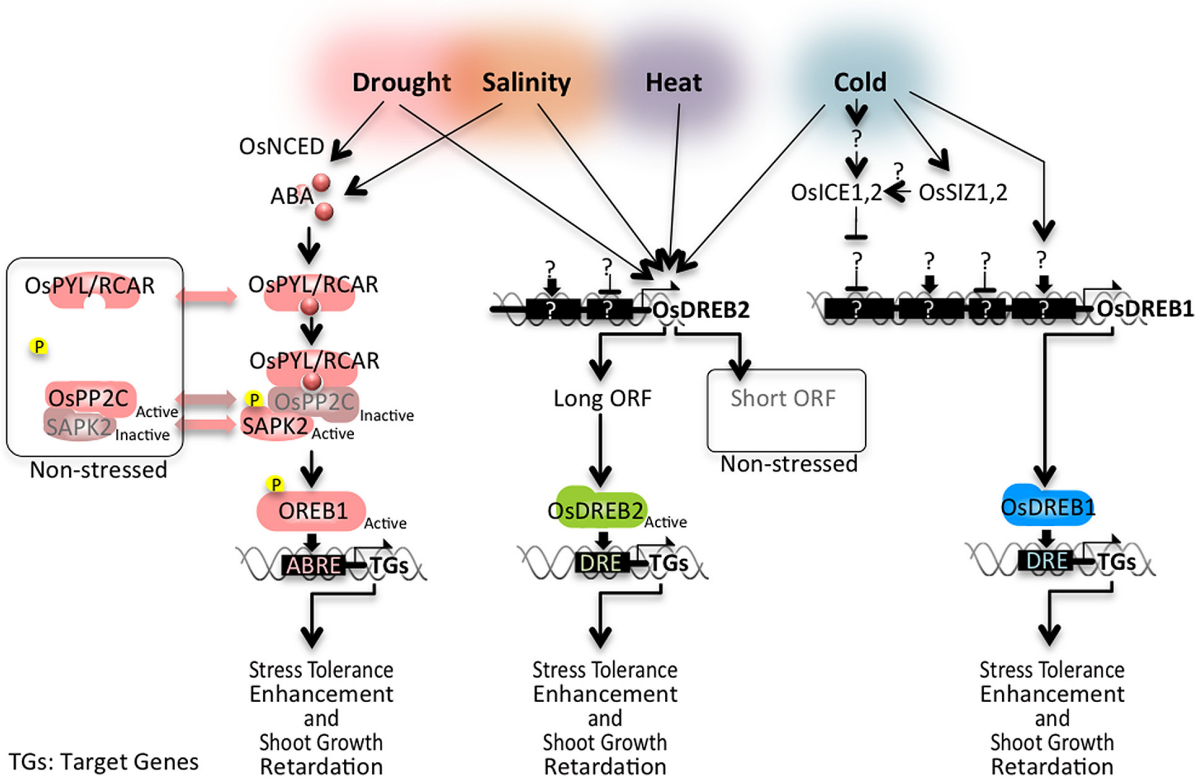

FIGURE 1 | Abiotic stress signaling networks mediated by AREB, DREB1, and DREB2-type transcription factors (A) in Arabidopsis and (B) in rice.

OsbZIP46 is a member of the subfamily that includes OsbZIP23. A transactivation assay conducted by Tang et al. (2012) revealed that an internal amino acid sequence (residues 122-219) of the OsbZIP46 protein had a negative affected on transactivation activity. A constitutively active form of OsbZIP46 (OsbZIP46CA1) was developed by deletion of this internal region. Transgenic rice plants overexpressing OsbZIP46CA1 showed increased drought tolerance. Microarray analysis was then used to detect upor down-regulated genes in the OsbZIP46CA1-overexpressing transgenic rice plants. These differentially regulated genes were largely different from the OsbZIP23 downstream genes, suggesting that OsbZIP46CA1 regulates a different set of genes than does
OsbZIP23. Although plant height under non-stressed conditions did not appear to differ between overexpressors and control plants, exogenous ABA application drastically decreased plant height of OsbZIP46CA1 overexpressors. Similar growth inhibition was observed in OsbZIP23 overexpressors. These results suggest that the ABA-dependent signaling pathway mediated by OsbZIP23 or OsbZIP46 is closely related to growth retardation mechanisms under drought stress conditions. This relationship implies that growth of transgenic rice plants overexpressing OsbZIP23 or OsbZIP46CA1 is decreased under drought stress conditions, even though transgenic plants exhibit increased stress tolerance. 


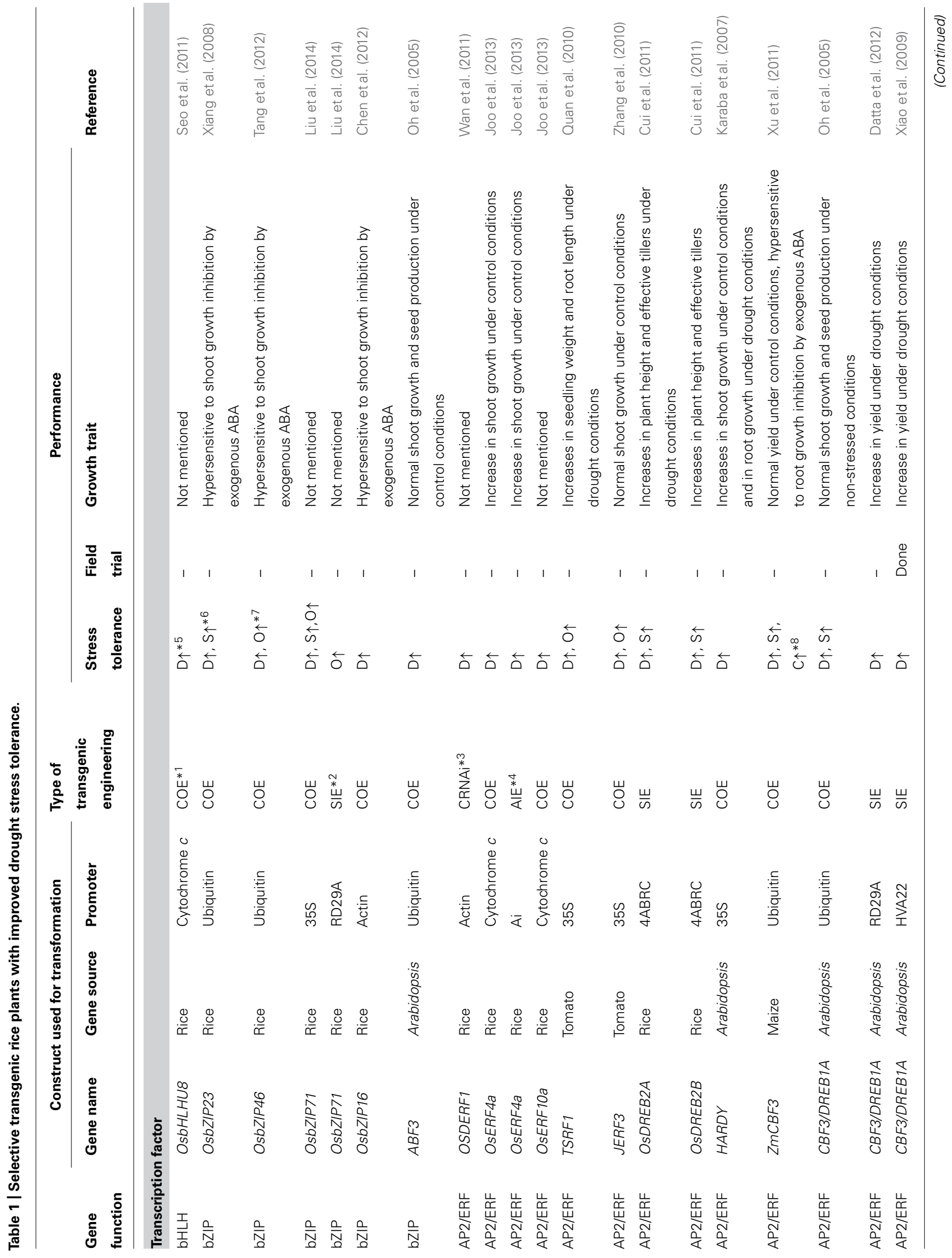




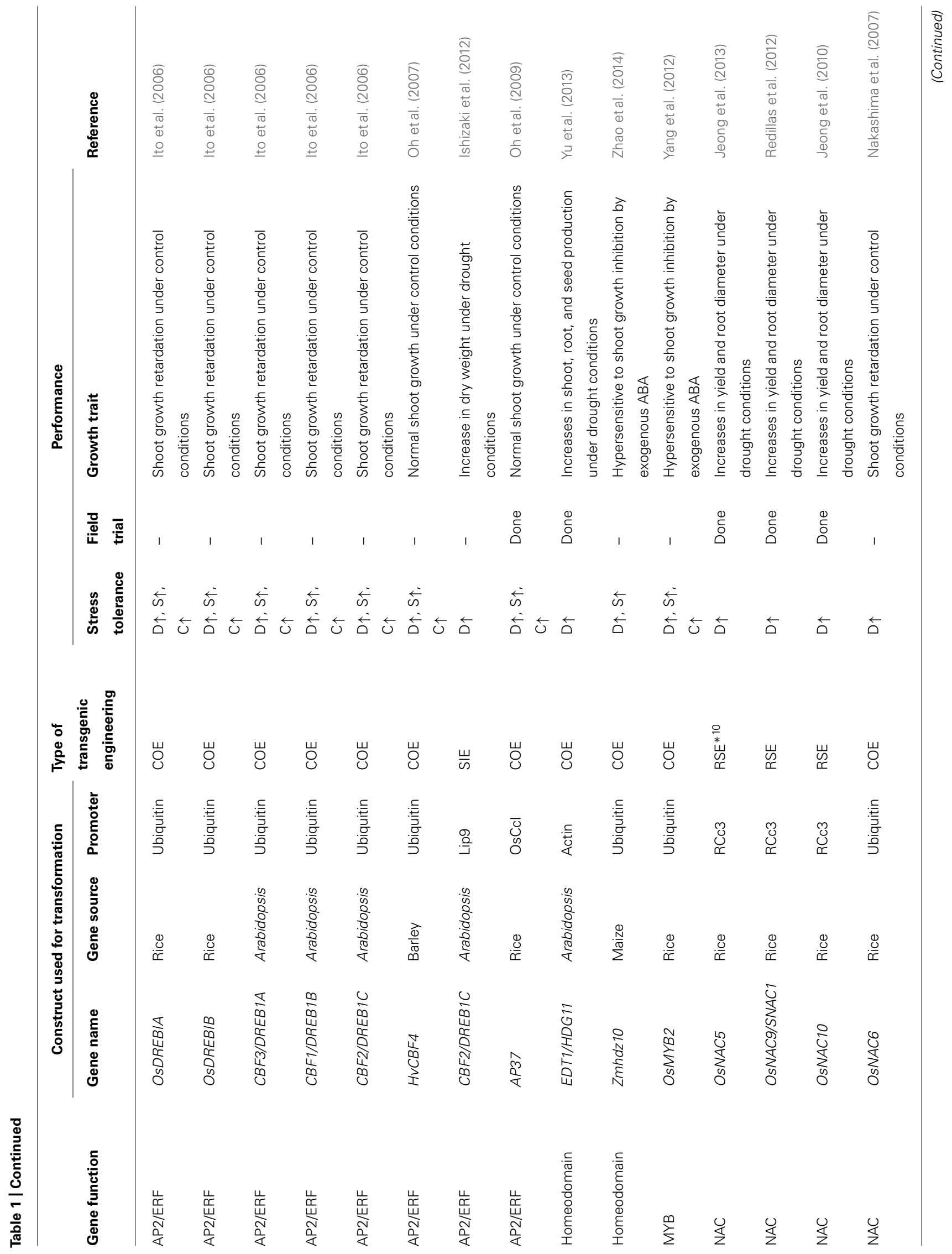




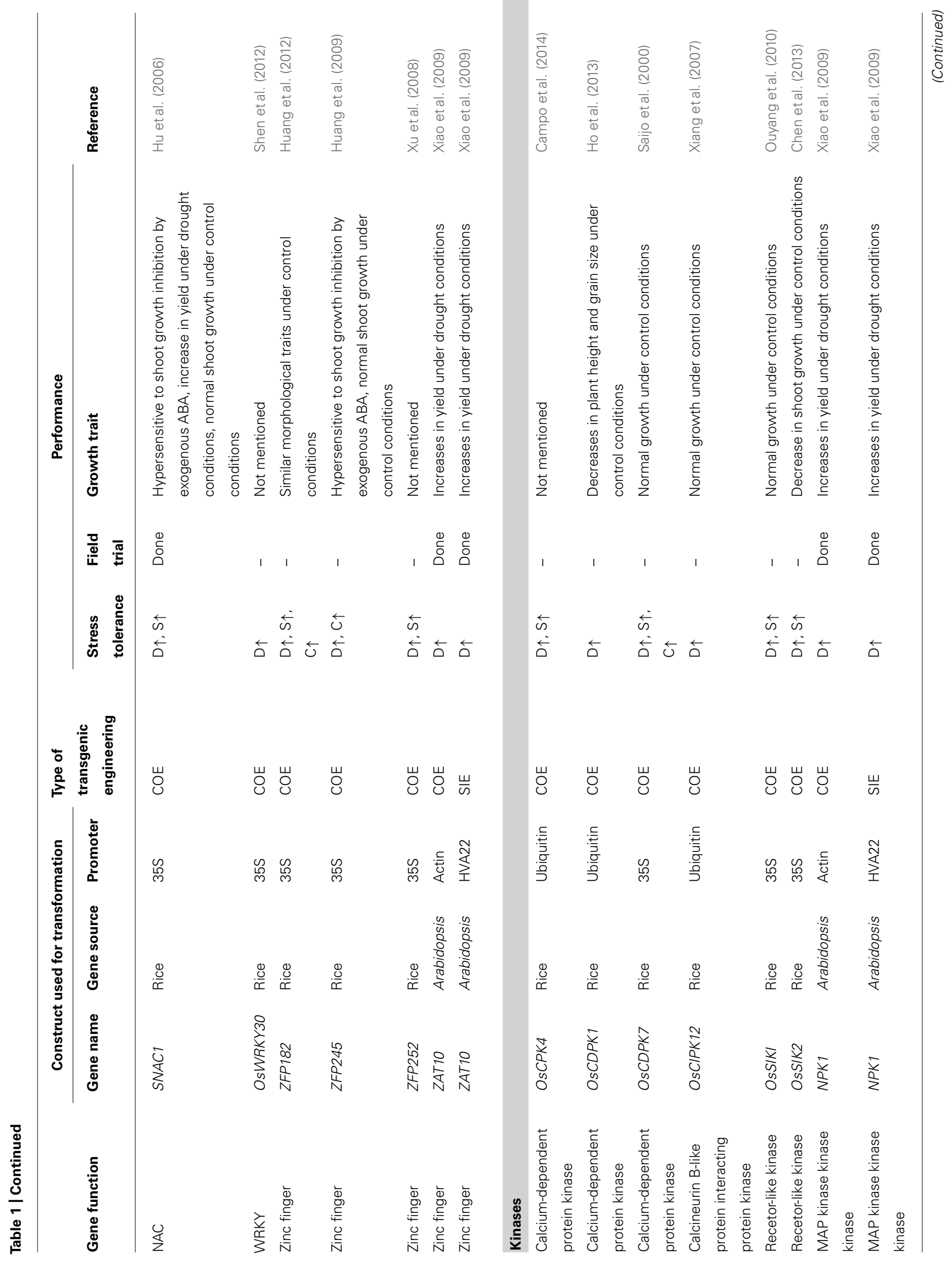




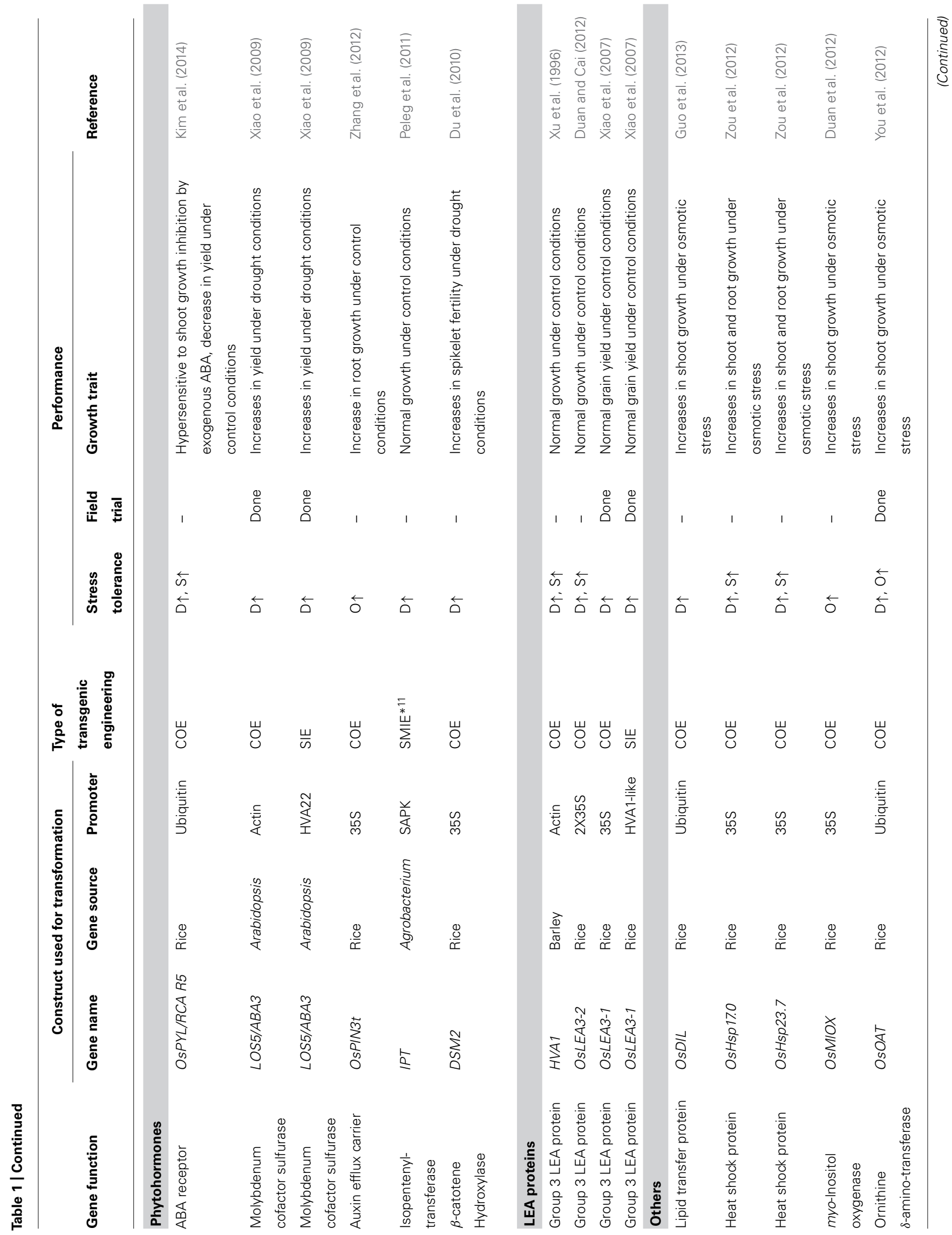




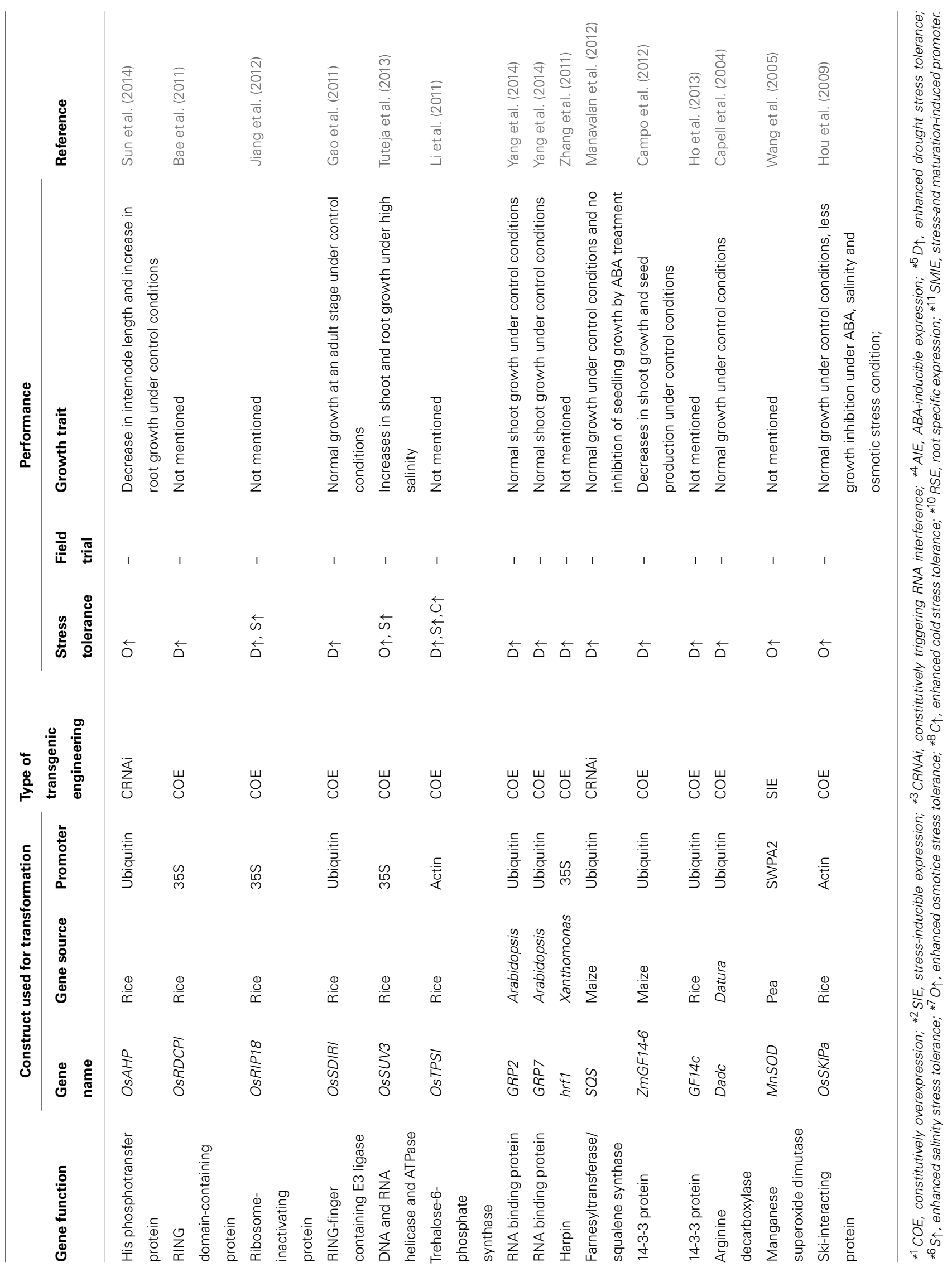


Arabidopsis ABF3 belongs to the same bZIP subfamily as OsbZIP46 and OsbZIP23. Transgenic Arabidopsis plants overexpressing $A B F 3$ show improved drought tolerance (Kang et al., 2002). Under non-stressed conditions, overexpressors are morphologically identical to control plants. Transgenic rice plants overexpressing $A B F 3$ have also been found to exhibit improved drought tolerance without growth inhibition (Oh et al., 2005).

OsbZIP16 and OsbZIP71 are classified into group IV of the rice bZIP subfamily, which is different than the Arabidopsis ABF/AREB subfamily (Nijhawan et al., 2008). Transgenic rice plants overexpressing OsbZIP16 show improved drought tolerance and increased growth inhibition under exogenous ABA treatment (Chen etal., 2012), while OsbZIP71-overexpressing plants under the $35 \mathrm{~S}$ promoter or a stress-inducible RD29A promoter exhibit improved drought, salt, and osmotic stress tolerance (Liu etal., 2014). Overexpression of these genes seems not to change plant architecture under non-stressed conditions.

These reports suggest that the bZIP-type transcription factors involved in the ABA signaling pathway are potentially useful for transgenic engineering to develop rice cultivars with enhanced drought tolerance. This notion is supported by the fact that ABA content in rice is increased by drought stress (Maruyama et al., 2014) and the finding that the ABRE cis-element is enriched in the promoter regions of drought-responsive genes in rice (Maruyama et al., 2012).

\section{AP2/ERF-TYPE TRANSCRIPTION FACTORS}

As mentioned above, the Arabidopsis DREB1A gene is a key regulator of abiotic stress response. At least three independent research groups have developed DREB1A-overexpressing transgenic rice plants. Oh et al. (2005) reported that overexpression of $D R E B 1 A$ driven by the ubiquitin promoter in rice plants enhances tolerance to drought and salinity stresses without growth retardation under non-stressed conditions. They observed up-regulated expression of several genes, including those responsive to stress, in transgenic rice plants. Datta et al. (2012) developed transgenic rice plants expressing DREB1A under the control of the stressinducible $R D 29$ promoter. The yield of the transgenic rice plants under drought stress conditions was increased compared with that of non-transgenic plants. Ito et al. (2006) also reported that transgenic rice plants overexpressing DREB1A with the ubiquitin promoter showed enhanced tolerance to drought, cold, and salinity stresses. Elevated contents of osmoprotectants such as free proline and soluble sugars were also observed. A microarray analysis detected up-regulated genes in the transgenic rice plants; among the uncovered genes were genes for $\alpha$-amylase and dehydrins, which were different from those identified by $\mathrm{Oh}$ et al. (2005). Unlike Oh et al. (2005), Ito et al. (2006) found that shoot growth retardation occurred in the transgenic plants under nonstressed conditions. Ito et al. (2006) also developed transgenic rice plants overexpressing $D R E B 1 A$ homologs, Arabidopsis paralogs $D R E B 1 B$ and $D R E B 1 C$ and rice orthologs OsDREB1A and $O s D R E B 1 B$ under the control of the ubiquitin promoter. These overexpressors showed enhanced tolerance to drought, salinity, and low temperature and displayed reduced growth under nonstressed conditions. Ishizaki et al. (2012) introduced Arabidopsis DREB1C into the upland rice cultivar NERICA1, an interspecific hybrid between stress-resistant O. glaberrima Steud. and highyield $O$. sativa. The transgenic rice plants showed improved survival under drought stress conditions. $H v C B F 4$, a member of the Arabidopsis DREB1A subfamily, has been isolated from barley as a low-temperature responsive gene. Overexpression of $\mathrm{HvCBF} 4$ was found to enhance tolerance to drought, salinity, and low temperature while shoot growth was unaffected (Oh et al., 2007). ZmCBF3, a maize AP2/ERF-type transcription factor, is also a member of the Arabidopsis DREB1A subfamily. In a study by $\mathrm{Xu}$ etal. (2011), overexpression of $\mathrm{ZmCBF3}$ in transgenic rice plants enhanced tolerance to drought, salinity, and low-temperature stresses. Yields under control conditions were unchanged in the overexpressors compared with those in non-transgenic plants.

As mentioned above, the physiological role and molecular function of Arabidopsis DREB2A in abiotic stress responses have been vigorously studied (Mizoi et al., 2012). Arabidopsis DREB2A is widely recognized as a master regulator of both drought and heat stress responses and has a high potential to enhance drought and heat stress tolerance (Mizoi et al., 2012). The DREB2 regulatory mechanism seems to be well conserved in various plant species. In rice, there are five DREB2 family genes: OsDREB2A, OsDREB2B, OsDREB2C, OsDREB2E, and OsABI4. Transgenic Arabidopsis plants overexpressing OsDREB2B are reported to show increased expression of DREB2A target genes and enhanced tolerance to drought and heat stresses (Matsukura etal., 2010). Transgenic rice plants overexpressing OsDREB2B have also been found to increase drought tolerance (Chen et al., 2008). Overexpression of OsDREB2A under the control of an ABA-responsive promoter in rice plants increased contents of soluble sugars and proline at the seedling stage, resulting in increases in osmotic and salinity stress tolerance (Cui et al., 2011). The transgenic rice plants exhibited increased plant height and effective tiller numbers at the reproductive stage following drought treatment.

In addition to DREB1A and DREB2 subfamily members, several AP2/ERF-type and AP2/ERF-like transcription factors have been used to develop transgenic rice plants with enhanced abiotic stress tolerance. The Arabidopsis HARDY gene is an AP2/ERFlike transcription factor that enhances drought and salinity stress tolerance (Karaba et al., 2007). Transgenic rice plants overexpressing HARDY show enhanced photosynthetic assimilation and reduced transpiration, leading to increased shoot and root biomass. OsDERF1 is a protein that directly interacts with the GCC box in the promoter regions of OsERF3 and OsAP2-39 (Wan et al., 2011). Knockdown of OsDERF1 increases ethylene biosynthesis and drought tolerance, suggesting that OsDERF1 modulates drought response via ethylene production. Transgenic rice plants overexpressing OsERF3 show decreased drought tolerance (Zhang et al., 2013). In contrast, Joo et al. (2013) have reported that overexpression of OsERF3/OsERF4a decreases expression levels of a repressor involved in defense responses, leading to increased drought tolerance and seedling shoot growth. Overexpression of a tomato ERF gene, TSRF1, was found to improve osmotic and drought tolerance without growth retardation in rice seedlings. The improvement was attributed to corresponding increases in the expression of genes encoding MYC and MYB-type transcription factors and genes related to 
ABA synthesis, proline synthesis, and photosynthesis (Quan et al., 2010). Another tomato ERF gene, JERF3, has also been observed to increase drought tolerance when overexpressed in transgenic rice plants (Zhang et al., 2010). The studied transgenic rice plants showed higher contents of soluble sugars and proline compared with those of non-transgenic plants. Transgenic rice plants overexpressing AP37, a rice AP2/ERF transcription factor, showed enhanced tolerance to drought, cold and high salinity stresses (Oh etal., 2009). Microarray analysis identified AP37 downstream genes, which included genes for PHD zinc finger and iron transporter.

Among the AP2/ERF transcription factor genes described here, $D R E B 1 / C B F$ genes have been widely used for the development of drought-tolerant transgenic crops. These developed crops include chrysanthemum (Hong et al., 2006), peanut (Bhatnagar-Mathur et al., 2013), soybean (Polizel et al., 2011), tobacco (Kasuga et al., 2004), tomato (Hsieh et al., 2002), tall fescue (Zhao et al., 2007), and wheat (Pellegrineschi et al., 2004).

\section{NAC-TYPE TRANSCRIPTION FACTORS}

NAC family proteins function in a wide variety of developmental processes and abiotic stress responses (Nakashima et al., 2012; Nuruzzaman et al., 2013). Constitutive overexpression of OsNAC6 in rice plants was observed to increase tolerance to drought and salinity stresses (Nakashima et al., 2007). The transgenic rice plants showed decreased shoot growth under non-stressed conditions. When a stress-inducible promoter was used for the transgene expression, the transgenic plants showed normal growth under non-stressed conditions and improved salinity stress tolerance. In the same study, microarray analysis revealed OsNAC6 downstream genes including stress-related genes. The transgenic rice plants constitutively overexpressing OsNAC6 also showed enhanced tolerance to blast disease, suggesting that OsNAC6 can act as a transcriptional regulator in both biotic and abiotic stress responses in rice.

In a study by Hu et al. (2006), SNAC1 was demonstrated to be predominantly expressed in guard cells under drought conditions. Transgenic rice plants overexpressing SNAC1 showed reduced water loss due to increased stomatal closure and enhanced expression of a large number of stress-related genes. As mentioned in the following section, the transgenic rice plants exhibited enhanced drought tolerance during field trials.

Transgenic rice plants overexpressing OsNAC10 under the control of a root-specific promoter showed thicker roots and higher grain yields than those of control plants under drought stress conditions (Jeong etal., 2010). An accompanying microarray analysis identified various downstream genes, including $P 450, \mathrm{Zn}$ finger, HAK5, 2OG-Fe(II), NCED, NAC, and KUP3 (Jeong et al., 2010). Similar to OsNAC10 overexpressors, transgenic rice plants overexpressing OsNAC5 (Jeong et al., 2013) and OsNAC9/SNAC1 (Redillas et al., 2012) under root-specific promoter control have been shown to have thicker roots and higher grain yields than control plants under drought stress conditions. The microarray analysis of Jeong et al. (2013) identified 62 downstream genes of OsNAC5, including NCED, calcium-transporting ATPase, germinlike protein, and meristem protein 5. Only 17 of these downstream genes were up-regulated in OsNAC10-overexpressing transgenic rice plants (Jeong et al., 2013). With respect to OsNAC9/SNAC1 overexpressors, identified downstream genes included NCED and calcium-transporting ATPase (Redillas et al., 2012). In addition to stress-responsive genes, OsNAC family downstream genes included genes involved in cell growth and development, suggesting that the OsNAC family is involved in regulatory mechanisms of stress responses and developmental processes. Song et al. (2011) observed that accumulations of proline and soluble sugars in OsNAC5 overexpressors were higher than those of non-transgenic plants. Takasaki et al. (2010) have reported that OsNAC5 functions as a transcriptional activator and up-regulates expression of some stress-responsive genes in OsNAC5 overexpressors. These authors also detected dimerization of OsNAC5 with OsNAC5, OsNAC5 with OsNAC6, and OsNAC5 with SNAC1.

\section{OTHER TRANSCRIPTION FACTORS}

Other transcription factors have also been applied in the successful development of transgenic rice plants with enhanced drought tolerance. Some of these plants have shown increased ABA sensitivity. Arabidopsis EDT1/HDG11 encodes a homeodomainleucine zipper transcription factor, which is likely involved in reproductive development (Yu et al., 2008). Overexpression of EDT1/HDG11 in rice plants has been found to enhance root development, reduce stomatal density, and increase water-use efficiency (Yu et al., 2013). In the cited study, levels of ABA, proline and soluble sugars and activities of reactive oxygen species (ROS)-scavenging enzymes under drought stress conditions were higher in transgenic rice plants than in non-transgenic ones. Global gene expression analysis showed that stress-responsive genes, including SNAC1, SNAC2, OsbZIP23, and OsNCED3, were up-regulated in the transgenic rice plants. Under drought stress conditions, the transgenic rice plants exhibited higher grain yields compared with non-transgenic plants. Zhao et al. (2014) isolated a maize homeodomain-leucine zipper transcription factor gene, $Z m h d z 10$, and generated transgenic rice plants overexpressing this gene. Overexpression of $Z m h d z 10$ enhanced tolerance to drought and salinity stresses and increased growth inhibition under exogenous ABA treatments. In another study, a rice R2R3-type MYB gene, OsMYB2, was overexpressed in rice plants (Yang et al., 2012). The transgenic overexpressors showed enhanced tolerance to drought, salinity and low-temperature stresses, and normal growth rates under non-stressed conditions. Exogenous ABA treatment resulted in greater growth inhibition of shoots of the overexpressors than those of non-transgenic plants.

Overexpression of OsWRKY30 in rice plants has been found to enhance drought tolerance (Shen etal., 2012). In contrast, no improved drought tolerance due to overexpression of OsWRKY3OAA, where all serine residues followed by proline are replaced by alanine residues in the encoded protein, has been observed. The observed interaction of these OsWRKY30 proteins with various MAP kinase proteins suggests that OsWRKY30 functions downstream of the MAPK cascades (Shen etal., 2012). A few studies have reported that overexpression of genes encoding $\mathrm{C} 2 \mathrm{H} 2$-type zinc finger transcription factors improves drought tolerance in transgenic rice plants. For 
example, ZFP182-overexpressing transgenic rice plants exhibit increased expression levels of OsDREB1A, OsDREB1B, OsP5CS, and $O s L E A 3$ and show enhanced tolerance to drought, salinity and low-temperature stresses (Huang et al., 2012), suggesting that ZFP182 may function in the upstream pathway of OsDREB1. Overexpression of ZFP245 in rice plants has been found to increase tolerance to drought and low-temperature stresses (Huang et al., 2009). Transgenic rice plants display elevated proline levels and ROS-scavenging enzyme activities. Overexpressing ZFP252 in rice plants leads to enhanced tolerance to drought and salinity stresses and increased proline and soluble sugar contents (Xu et al., 2008). Increased drought tolerance has been observed in transgenic rice plants overexpressing OsbHLH148, a gene encoding MeJA-responsive transcription factor (Seo et al., 2011). In the cited study, expression of OsDREB1 and OsJAZ family genes was up-regulated in the overexpressors, and OsJAZ and OsCOI1 proteins were demonstrated to interact with one another. These results suggest that OsbHLH148 acts on the JA signaling cascade with OsJAZ1 and OsCOI1 and functions as an upstream regulator of OsDREB1.

\section{PROTEIN KINASES}

Transgenic rice plants overexpressing OsCPK4, a calciumdependent protein kinase, showed enhanced tolerance to drought and salinity stresses in a study by Campo et al. (2014). In the overexpressors, genes related to lipid metabolism, such as those encoding proteins with lipid binding activities, lipid transfer proteins, and lipases, were up-regulated. Oxidative stress-responsive genes, including peroxidase, thioredoxin, GST, and laccase genes, were also up-regulated in the transgenic plants. These findings suggest that OsCPK4 is involved in the regulation of cellular membrane protection against oxidative damage (Campo et al., 2014). Ho et al. (2013) isolated OsCDPK1 from sucrose-starved rice suspension cells and developed OsCDPK1-overexpressing transgenic rice plants. The transgenic rice plants displayed improved drought tolerance and activated (Ho et al., 2013) expression of a gene for a 14-3-3 protein, GF14c. Transgenic rice plants overexpressing GF14c also showed improved drought tolerance, suggesting that enhanced drought tolerance due to OsCDPK1 may be mediated by GF14c. Campo et al. (2012) have reported that transgenic rice plants overexpressing the gene encoding ZmGF14-6, a maize 143-3 protein, show enhanced drought tolerance. In their study, expression of stress-responsive genes, including Rab21 and Dip1, was higher under drought stress conditions in transgenic rice plants than in non-transgenic ones, with transgenic plants also exhibiting a higher susceptibility to infection by fungal pathogens. These observations indicate that ZmGF14-6 functions as a positive regulator in abiotic stress response, but as a negative regulator in biotic stress response. Saijo et al. (2000) discovered that transgenic rice plants overexpressing $O s C D P K 7$ showed elevated tolerance to drought, salinity, and low-temperature stresses. Overexpression of OsCDPK7 increased the expression of several stress-responsive genes, suggesting that OsCDPK7 is a positive regulator of abiotic stress response. Finally, transgenic rice plants overexpressing OsCIPK12 have been found to exhibit enhanced drought tolerance, with increased accumulation of proline and soluble sugars (Xiang et al., 2007).

\section{RECEPTOR-LIKE KINASES}

OsSIK1 is a putative receptor-like kinase (RLK) with extracellular leucine-rich repeats (Ouyang et al., 2010). In the study by Ouyang et al. (2010), transgenic rice plants overexpressing OsSIK1 showed enhanced tolerance to drought and salinity stresses. Leaves of the transgenic plants exhibited elevated peroxidase, superoxide dismutase and catalase activities and reduced accumulation of $\mathrm{H}_{2} \mathrm{O}_{2}$ compared with those of non-transgenic plants. Reduced stomatal density was also observed in the transgenic plants, suggesting that OsSIK1 may act as a negative regulator for stomatal development. Another rice RLK, OsSIK2, has been reported by Chen etal. (2013). In their study, OsSIK2 was predicted to be an S-domain RLK. Transgenic rice plants overexpressing OsSIK2 showed enhanced tolerance to drought and salinity stresses, early leaf development, and a delayed dark-induced senescence phenotype. Their results suggest that OsSIK2 is involved in abiotic stress response and senescence processes.

\section{LEA PROTEINS}

Late embryogenesis abundant (LEA) proteins are important stressinducible proteins involved in cellular protection against stresses (Hanin et al., 2011). Their protective roles in cells include cryoprotective (Bravo et al., 2003) and osmoprotective (Swire-Clark and Marcotte, 1999) behavior to stabilize proteins (Grelet et al., 2005), membranes (Koag et al., 2003), and glassy states (Wolkers et al., 2001). For example, recombinant pea LEA proteins have been shown to protect two mitochondrial matrix enzymes, fumarase, and rhodanese, during drying (Grelet et al., 2005). After transgenically introducing several LEA proteins into rice plants, Hong et al. (1988) investigated stress tolerance in the transgenic rice plants. A barley group-3 LEA protein, HVA1, was specifically accumulated in aleurone layers and embryos at the seed maturation stage. In another study, HVA1-overexpressing transgenic rice plants were found to have increased tolerance to drought and salinity stresses, with the increased stress tolerance correlated with HVA1 protein accumulation (Xu et al., 1996). Overexpression of OsLEA3-1 or OsLEA3-2 in rice plants leads to enhanced drought tolerance (Xiao et al., 2007; Duan and Cai, 2012). Overexpression of OsLEA3-2 in yeast improved growth under salinity or osmotic stress conditions, with the OsLEA3-2 protein inhibiting protein aggregation in an in vitro assay (Duan and Cai, 2012).

\section{PHYTOHORMONES}

OsPYL/RCAR5 has been shown to be one of the ABA-signaling components in rice (Kim et al., 2012b). A protein-protein interaction assay and a transient gene expression assay performed by these authors identified an ABA-signaling unit composed of OsPYL/RCAR5, OsPP2C30, SAPK2, and OREB1. Kim et al. (2014) found that overexpression of OsPYL/RCAR5 induced expression of numerous stress-responsive genes in rice and caused enhanced tolerance to drought and salinity stresses; however, field-grown transgenic rice plants had shorter heights and lower yields than their non-transgenic counterparts. DSM2 encodes a chloroplast protein, a putative $\beta$-carotene hydroxylase involved in biosynthesis of the ABA precursor zeaxanthin (Du et al., 2010). Overexpression of DSM2 in rice plants 
enhanced resistance to drought and oxidative stresses and increased xanthophyll levels and non-photochemical quenching.

Zhang etal. (2012) identified and investigated OsPIN3t, a putative auxin efflux carrier protein in rice. GFP proteins fused to OsPIN3t were expressed in the plasma membrane, while GUS activity in OsPIN3t promoter-driven GUS transgenic plants was detected in vascular tissues. These subcellular expressions and tissue-specific localization were changed by treatment with auxin transport inhibitors. Transgenic rice plants overexpressing OsPIN3t exhibited improved drought tolerance. These results suggest that OsPIN3t regulates polar auxin transport, thereby enhancing drought tolerance.

Isopentenyltransferase (IPT) is an enzyme that mediates cytokinin synthesis. Transgenic tobacco plants expressing the IPT gene under the control of a senescence-associated receptor kinase (SAPK), a maturation- and stress-inducible promoter, were developed by Rivero et al. $(2007,2009)$. The transgenic tobacco plants showed a drastic increase in plant productivity under drought stress conditions. The observed increased plant productivity was attributed to suppression of drought-induced leaf senescence (Rivero et al., 2007) and involvement in photorespiration (Rivero et al., 2009). Similarly, transgenic rice plants expressing the IPT gene under the control of the SAPK promoter were generated (Peleg et al., 2011). The developed transgenic rice plants displayed expression changes in genes involved in hormone homeostasis and resource mobilization, a delay in stress responses, and improvement of drought tolerance. In a study by Sun et al. (2014), two rice authentic histidine phosphotransfer proteins (OsAHP1 and OsAHP2) were knocked down simultaneously via RNA interference. The transgenic rice plants showed enhanced tolerance to osmotic stress and hyposensitivity to exogenous cytokinin, suggesting that OsAHPs function as positive regulators of the cytokinin signaling pathway in response to osmotic stress.

\section{OSMOPROTECTANTS}

Ornithine $\delta$-aminotransferase is involved in proline and arginine metabolism. OsOAT, a rice gene encoding ornithine $\delta$ aminotransferase, has been identified as a downstream gene of SNAC2 (Hu et al., 2008). You et al. (2012) demonstrated that SNAC2 can bind to the OsOAT promoter. In their study, overexpression of the OsOAT gene in rice plants enhanced $\delta$-OAT activity and increased proline accumulation, glutachione content, and ROS-scavenging enzyme activity. The OsOAT-overexpressing transgenic rice plants displayed enhanced oxidative, drought, and osmotic stress tolerance. While seedling shoot lengths were similar between transgenic and non-transgenic plants under normal conditions, reduced inhibition of shoot growth was observed in transgenic plants under osmotic stress conditions compared with non-transgenic plants.

OsTPS1, a gene encoding a rice trehalose-6-phosphate synthase, acts as a key enzyme for trehalose biosynthesis. Overexpression of the gene in rice plants improved tolerance to drought, salinity, and low-temperature stresses in an investigation by Li et al. (2011). In the transgenic rice plants, trehalose and proline contents were increased and some stress-responsive genes, including WSI18, were up-regulated relative to those in non-transgenic plants.

\section{OTHER GENES}

Other genes encoding proteins with various characteristics have also been shown to enhance drought tolerance. Some of these proteins are stress responsive. The effect of overexpression of O. sativa Drought-Induced LTP (OsDIL), a lipid transfer protein gene, on drought stress tolerance in rice was investigated by Guo etal. (2013). The transgenic plants showed increased tolerance to drought stress at both vegetative and reproductive stages. Less severe tapetal defects and fewer defective anther sacs were observed in the transgenic plants. These results were consistent with data indicating that the OsDIL gene is expressed in anthers. Overexpression of the heat shock protein gene OsHsp17.0, or OsHsp23.7, has been found to improve tolerance to drought and salinity stresses in rice (Zou etal., 2012). In that study, the transgenic rice plants had lower relative electrical conductivities and malondialdehyde contents and higher proline contents compared with non-transgenic rice plants.

Modulation of ROS accumulation is also important for the enhancement of drought tolerance. Transgenic rice plants overexpressing the gene encoding manganese superoxide dismutase, an antioxidant enzyme, have improved osmotic stress tolerance (Wang et al., 2005). The cited authors found that electrolyte leakage in the transgenic plants was lower than in non-transgenic plants under osmotic stress conditions, and that photosynthetic rate was less affected by osmotic stress in the transgenic plants. The enzyme OsMIOX, a rice myo-inositol oxygenase, catalyzes the oxidation of myo-inositol to glucuronic acid. In a study by Duan etal. (2012), the OsMIOX gene was overexpressed in rice plants and caused increases in ROS-scavenging enzyme activities and proline content and enhancement of growth performance under osmotic stress conditions. Ski-interacting protein (SKIP), identified by yeast two-hybrid screening using the avian retrovirus oncogene v-Ski as bait (Dahl et al., 1998), has been well characterized as a transcriptional coregulator and a spliceosome component in humans (Figueroa and Hayman, 2004). Transgenic rice plants overexpressing OsSKIPa have shown improved drought tolerance and increased ROS-scavenging ability. Higher transcript levels of SNAC1, OsCBF2, OsPP2C, and $O s R D 22$ have been found in OsSKIPa-transformed rice plants compared with their non-transgenic counterparts (Hou et al., 2009).

Protein turnover via ubiquitin-dependent protein degradation and ribosomal protein synthesis has been shown to be involved in abiotic stress response regulatory networks. OsSDIR1 ( $O$. sativa SALT-AND DROUGHT-INDUCED RING FINGER 1) is a functional RING-finger-containing E3 ligase, with the RING finger region required for its activity (Gao et al., 2011). Transgenic rice plants overexpressing OsSDIR1 show enhanced drought tolerance and stomatal closure (Gao etal., 2011), while those overexpressing OsRDCP1, a rice RING domain-containing protein 1 gene, have improved drought tolerance (Bae et al., 2011). Molecular mechanisms underlying the improved drought tolerance of these transgenic rice plants remain largely unclear. Jiang et al. (2012) observed that transgenic rice plants overexpressing OSRIP18, a rice ribosome-inactivating protein 18 gene, exhibited improved drought and salinity tolerance. Microarray 
analysis detected differentially expressed genes, most of which were not regulated by abiotic stresses, in the transgenic rice plants.

RNA turnover may also be involved in abiotic stress-response regulatory networks. OsSUV3 encodes an NTP-dependent RNA/DNA helicase (Tuteja et al., 2013). Transgenic rice plants overexpressing OsSUV3 show reduced lipid peroxidation, electrolyte leakage, and $\mathrm{H}_{2} \mathrm{O}_{2}$ production, and enhanced antioxidant enzyme activities, thereby leading to enhanced tolerance to osmotic and salinity stresses (Tuteja et al., 2013). GRP encodes a glycine-rich RNA-binding protein. In a study by Yang et al. (2014), transgenic rice plants overexpressing Arabidopsis GRP2 or GRP7 displayed increased grain yield under drought conditions. The increased grain yield was caused by improved grain filling. Several stress-responsive genes, including OSE2, Dip1, and $P B Z 1$, were up-regulated in the transgenic rice plants.

The application of genes encoding metabolic enzymes is also thought to be useful for the enhancement of drought tolerance. Squalene synthase (SQS) is one of several farnesyl-diphosphate farnesyltransferase proteins that catalyze the first reaction of the branch of the isoprenoid metabolic pathway involved in sterol biosynthesis (Tansley and Shechter, 2001). Disruption of SQS gene function by RNA interference has been found to improve drought tolerance in rice plants, with the transgenic plants showing increased root length, an elevated number of lateral roots and reduced stomatal conductance (Manavalan et al., 2012). Polyamines, such as putrescine, spermidine, and spermine, are compounds implicated in plant embryo development, stem elongation and stress response (Takahashi and Kakehi, 2010). Polyamine levels can be modulated by the regulation of metabolic enzymes, including arginine decarboxylase. Because rice plants overexpressing Datura stramonium arginine decarboxylase show improved drought tolerance along with increased putrescine content, Capell et al. (2004) have proposed a regulatory mechanism linking putrescine metabolism to drought tolerance. In contrast to putrescine, spermidine, and spermine are not involved in drought stress tolerance, as increased spermidine and spermine content has not been observed to enhance drought tolerance in rice plants (Peremarti etal., 2009).

Transgenes originating from non-plant species have also been used to enhance stress tolerance. Harpin proteins are secreted by the type-III protein secretion system of Gramnegative plant pathogenic bacteria (Wei et al., 1992). Harpin proteins trigger the hypersensitive response, a well-characterized defense response against various bacteria, fungi, nematodes, and viruses. Transgenic rice plants overexpressing the harpinencoding gene hrfl showed improved drought tolerance along with increased stomatal clousure and ABA, proline, and soluble sugar contents (Zhang etal., 2011). Increased expression of stress-responsive genes including OsLEA3-1 was also observed in the transgenic rice plants. As reviewed by Sharma etal. (2013), the evidence that pathogenic-related genes can also improve abiotic stress tolerance suggests an overlapping regulatory cascade between biotic and abiotic stresses.

\section{CHANGES IN SHOOT GROWTH OF DROUGHT-TOLERANT TRANSGENIC RICE PLANTS}

Among the transgenic rice plants described in this review, 37\% have been reported to display growth retardation under normal conditions or exogenous ABA application (Table 1). Such decreased shoot growth performance is also observed in nontransgenic plants subjected to drought stress conditions. Shoot growth retardation due to low soil water content is one of the earliest stress responses in plants, occurring even earlier than decreases in leaf water potential (Michelena and Boyer, 1982; Parent et al., 2010). This phenomenon suggests that plants actively decrease shoot growth instead of it being a consequence of decreased cell turgor (Claeys and Inzé, 2013). Growth regulation in proportion to soil water content is thus an important plant morphological response to water deficit. Molecular mechanisms underlying growth regulatory responses to water deficit have been investigated in Arabidopsis. DELLA proteins, which are negative regulators of gibberellic acid (GA) signaling, have been shown to integrate growth and abiotic stress tolerance in Arabidopsis (Achard et al., 2006). Skirycz et al. (2010) performed transcript profiling of expanding Arabidopsis leaves subjected to mild osmotic stress. Their results indicated that an ethyleneand gibberellin-dependent regulatory circuit modulated growth under the mild osmotic stress conditions, with no involvement from ABA. Rapid accumulation of 1-aminocyclopropane1-carboxylic acid (1-ACC), an ethylene precursor, was observed in the expanding leaf tissue under the mild osmotic stress conditions of their study. This accumulation has been proposed to activate a cascade of the growth regulatory circuit in Arabidopsis as follows (Claeys and Inzé, 2013). After activation by 1-ACC accumulation through a MAP kinase cascade, ethylene responsive factor 6 (ERF6) increases expression of GA2OX6, which encodes an enzyme that inactivates GAs. By the operation of GA2OX6, GAs are inactivated, with this inactivation stabilizing DELLA proteins. The DELLA proteins modulate the activity of ANAPHASE-PROMOTING COMPLEX/CYCLOSOME (APC/C), which controls the activity of CDK-cyclin complexes, through the repression of APC/C inhibitors DEL1 and UVI4. Finally, the modulated APC/C activity abolishes potential for cell proliferation and inhibits growth.

A similar growth regulatory circuit does not seem to hold for rice, as it has been generally accepted that ethylene and 1-ACC act as positive growth regulators under various conditions in rice (Bailey-Serres and Voesenek, 2008, 2010; Fukao and Xiong, 2013; Wang et al., 2013). In rice, growth regulatory mechanisms that are distinct from those in Arabidopsis should therefore be taken into consideration. We recently identified $O$. sativa phytochrome interacting factor like 1 (OsPIL1), a gene that regulates internode elongation under drought stress conditions in rice (Todaka et al., 2012). The bHLH-type transcription factor OsPIL1 functions as a transcriptional activator and modulates expression of cell elongation-related genes such as expansins. Increased expression of OsPIL1 observed in the daytime under normal growth conditions was canceled under drought stress conditions. We proposed the following growth regulatory mechanistic model involving OsPIL1 in response to drought stress. Under normal growth conditions, OsPIL1 elevates expression of 
cell elongation-related genes such as expansins, causing normal shoot growth. When rice plants are exposed to drought stress, the canceled OsPIL1 expression leads to reduced expression of cell elongation-related genes, resulting in shoot growth reduction that likely conserves photosynthetic products and decreased shoot surface area. The saved energy may be used for activation of mechanisms involved in stress tolerance. Ogawa et al. (2011) have revealed that the rice protein RSS1 plays an important role in the maintenance of meristematic activity under salinity stress conditions. RSS1 proteins interact with protein phosphatase 1 , a regulator of various cellular processes including the cell division cycle. RSS1 stability is regulated by the APC/C 26S proteasome pathway, which is responsible for degradation of mitotic cyclins.

Use of the growth regulatory genes described in this section may ameliorate the growth reduction observed in drought-tolerant transgenic rice plants. Although stress-inducible promoters are often useful for development, their efficacy seems to be limited under moderate long-term drought stress conditions. Long-term drought stress maintains a high level of transgene expression, thereby affecting growth performance.

\section{EVALUATION OF ABIOTIC STRESS TOLERANCE UNDER FIELD CONDITIONS}

When developing abiotic stress tolerant transgenic crops, plant productivity should be taken into consideration. Plant productivity is extensively affected by natural drought episodes under field conditions. Droughts are unpredictable events and vary in stress severity and duration. Simultaneously occurring stresses, such as drought and heat, are also observed. Results obtained under laboratory or greenhouse conditions are therefore not perfectly comparable to observations made under field conditions. Field trials are thus critical for the proper evaluation of stress-tolerant transgenic crops.

Xiao et al. (2007) analyzed drought tolerance of transgenic rice plants constitutively overexpressing OsLEA3-1, a gene encoding proteins that highly accumulate in water-stressed tissues, as well as plants expressing the transgene with a stress-inducible promoter under field conditions. Drought stress was initiated at the panicle development stage by draining surface water in paddy fields and halting irrigation until leaves were rolled. Although $\mathrm{T}_{1}$ generations of both transgenic lines showed reduced yields under non-stressed conditions, $\mathrm{T}_{2}$ and $\mathrm{T}_{3}$ generations exhibited no yield penalty under non-stressed conditions and exhibited increased grain yield under drought conditions.

Xiao et al. (2009) also examined drought tolerance of transgenic rice plants overexpressing seven well-documented stress-related genes with an actin promoter under field conditions. These seven genes were $C B F 3 / D R E B 1 A$, an AP2/ERF-type transcription factor; SOS2, a serine/threonine protein kinase; NCED2 and LOS5, enzymes involved in ABA biosynthesis; NPK1, a mitogenactivated protein kinase kinase kinase; ZAT10, a C2H2-type zinc finger transcription factor; and $N H X 1$, a vacuolar $\mathrm{Na}^{+} / \mathrm{H}^{+}$ antiporter. Although drought stress in the field decreased grain yield in these transgenic plants, grain yields in LOS5, ZAT10, and NHX1 overexpressors were less affected. The authors also developed transgenic rice plants that expressed these genes with a stress-inducible promoter and field-tested their drought tolerance. Grain yields in these transgenic plants were similarly decreased by drought stress under field conditions. Grain yields in transgenic rice plants expressing CBF3/DREB1A, SOS2, NPK1, LOS5, $Z A T 10$, and NHX1 with the stress-inducible promoter were the least affected. Because absolute grain yields under normal growth conditions were lower in these transgenic rice plants than in non-transgenic ones, further improvement is needed for practical application.

$\mathrm{Hu}$ et al. (2006) subjected field-grown transgenic rice plants overexpressing SNAC1, a NAC-type transcription factor, to two different levels of drought stress treatments at the anthesis stage: severe stress with $15 \%$ soil moisture and moderate stress with $28 \%$ soil moisture. Both drought stress conditions increased spikelet fertility in the transgenic plants. Under non-stressed conditions, agronomic traits, including plant height, panicle number, spikelet number, spikelet fertility, and grain yield, were similar between transgenic plants and the controls. Drought resistance of transgenic rice plants overexpressing OsNAC5 (Jeong et al., 2013), OsNAC9/SNAC1 (Redillas et al., 2012), or OsNAC10 (Jeong etal., 2010) under the control of the root-specific promoter has also been examined in the field. In these studies, exposure to drought stress was performed at the panicle heading stage by draining surface water and halting irrigation until leaves were rolled. Similar results were observed among the three transgenic rice lines. Grain yield decreases under drought conditions were significantly smaller in all three transgenic lines than those observed in their non-transgenic counterparts. Drought tolerance of transgenic rice plants overexpressing OsOAT has also been investigated under field conditions (You et al., 2012). The OsOAT protein, an enzyme that increases proline content, is a direct target gene of the stress-responsive NAC transcription factor SNAC2. The field drought test was performed by stopping irrigation at the flowering stage in a refined paddy field covered with a movable rain-off shelter. Slower wilting, fewer withered leaves, and a higher rate of seed-setting were noted in the transgenic rice plants than in non-transgenic ones.

Increased grain yield was observed in transgenic rice plants overexpressing the AP37 gene, an AP2/ERF-type transcription factor, when the transgenic plants were subjected to drought stress in the field (Oh et al., 2009). The field drought stress was performed at the panicle heading stage by draining the surface water and halting irrigation until leaves were rolled. The increased grain yield was due to the higher grain-filling rate in the droughttreated transgenic plants compared with the drought-treated non-transgenic plants. Finally, field evaluation of transgenic rice plants overexpressing EDT1/HDG11, a homeodomain-leucine zipper transcription factor, has also been carried out (Yu et al., 2013). The transgenic rice plants were grown in the field for a month after transplanting; irrigation was then stopped until the seed maturation stage. The drought-treated transgenic rice plants had higher grain yields than those observed in the droughttreated non-transgenic rice plants. The grain yield increase in the transgenic plants was a consequence of their larger panicle sizes and higher tiller numbers compared with the non-transgenic plants. 


\section{FUTURE DIRECTIONS IN THE DEVELOPMENT OF DROUGHT-TOLERANT TRANSGENIC RICE PLANTS}

Although several studies have reported transgenic rice plants with improved drought tolerance during field trials, further research is needed to uncover the regulatory mechanism of drought response and tolerance under field conditions. Such investigations should lead to the discovery of new genes that increase drought tolerance without yield penalty even under drought conditions. Another approach to new gene exploration is to study stress tolerance mechanisms of stress-adapted extremophiles such as desert plants, halophilic plants, cold-water fishes, and thermophilic bacteria (Mittler and Blumwald, 2010). Even in well-characterized species, the functions of $18-38 \%$ of total proteins remain unknown (Gollery etal., 2006). The elucidation of these unknown function proteins should aid the discovery of new genes. Modification of root architecture is also important for the development of drought-tolerant rice plants. In this regard, Uga et al. (2013) reported that the QTL Deeper Rooting 1 (DRO1) increased the root growth angle in rice, leading to high-yield performance under drought conditions.

Rice has the highest potential of any crop to grow under submergence conditions. Studies of submergence-tolerance mechanisms and the development of submergence-tolerant rice cultivars have progressed significantly (Bailey-Serres and Voesenek, 2008, 2010; Hattori et al., 2009; Fukao and Xiong, 2013; Voesenek and Bailey-Serres, 2013). The results of these studies indicate that drought-tolerant rice plants with submergence-tolerant cultivar backgrounds are exceptional crops that can survive under both low and excessive soil-water content conditions. In the future, crops may be alternately exposed to drought and flood because of global climate change. Efforts to develop rice cultivars having high water usage flexibility should help solve this crisis.

\section{AUTHOR CONTRIBUTIONS}

DT wrote all sections of the manuscript with the assistance of KS and KYS.

\section{ACKNOWLEDGMENTS}

We are grateful to Etsuko Toma for skillful editorial assistance. This work was supported by a Grant-in-Aid for Young Scientists (B) (No. 25850007) and a Grant-in-Aid for Scientific Research on Innovative Areas (No. 22119004) from the Ministry of Education, Culture, Sports, Science and Technology of Japan (MEXT), the Program for the Promotion of Basic Research Activities for Innovative Biosciences (BRAIN) of Japan, and the Science and Technology Research Partnership for Sustainable Development (SATREPS) of the Japan Science and Technology Agency (JST)/Japan International Cooperation Agency (JICA).

\section{REFERENCES}

Achard, P., Cheng, H., De Grauwe, L., Decat, J., Schoutteten, H., Moritz, T., et al. (2006). Integration of plant responses to environmentally activated phytohormonal signals. Science 311, 91-94. doi: 10.1126/science.1118642

Agarwal, M., Hao, Y., Kapoor, A., Dong, C.-H., Fujii, H., Zheng, X., et al. (2006). A R2R3 type MYB transcription factor is involved in the cold regulation of CBF genes and in acquired freezing tolerance. J. Biol. Chem. 281, 37636-37645. doi: 10.1074/jbc.M605895200

Bae, H., Kim, S. K., Cho, S. K., Kang, B. G., and Kim, W. T. (2011). Over expression of OsRDCP1, a rice RING domain-containing E3 ubiquitin ligase, increased tolerance to drought stress in rice (Oryza sativa L.). Plant Sci. 180, 775-782. doi: 10.1016/j.plantsci.2011.02.008

Bailey-Serres, J., and Voesenek, L. A. (2008). Flooding stress: acclimations and genetic diversity. Annu. Rev. Plant Biol. 59, 313-339. doi: 10.1146/annurev.arplant.59.032607.092752

Bailey-Serres, J., and Voesenek, L. A. (2010). Life in the balance: a signaling network controlling survival of flooding. Curr. Opin. Plant Biol. 13, 489-494. doi: 10.1016/j.pbi.2010.08.002

Bartels, D., and Sunkar, R. (2005). Drought and salt tolerance in plants. Crit. Rev. Plant Sci. 24, 23-58. doi: 10.1080/07352680590910410

Bauer, H., Ache, P., Lautner, S., Fromm, J., Hartung, W., Al-Rasheid, K. A. S., et al. (2013). The stomatal response to reduced relative humidity requires guard cellautonomous ABA synthesis. Curr. Biol. 23, 53-57. doi: 10.1016/j.cub.2012.11.022

Behnam, B., Iuchi, S., Fujita, M., Fujita, Y., Takasaki, H., Osakabe, Y., et al. (2013). Characterization of the promoter region of an Arabidopsis gene for 9-cisepoxycarotenoid dioxygenase involved in dehydration-inducible transcription. DNA Res. 20, 315-324. doi: 10.1093/dnares/dst012

Bhatnagar-Mathur, P., Rao, J. S., Vadez, V., Dumbala, S. R., Rathore, A., YamaguchiShinozaki, K., etal. (2013). Transgenic peanut overexpressing the DREB1A transcription factor has higher yields under drought stress. Mol. Breeding 33, 327-340. doi: 10.1007/s11032-013-9952-7

Bravo, L. A., Gallardo, J., Navarrete, A., Olave, N., Mart $\iota$ nez, J., Alberdi, M., et al. (2003). Cryoprotective activity of a cold-induced dehydrin purified from barley. Physiol. Plant. 118, 262-269. doi: 10.1034/j.1399-3054.2003.00060.x

Campo, S., Baldrich, P., Messeguer, J., Lalanne, E., Coca, M., and San Segundo, B. (2014). Overexpression of a calcium-dependent protein kinase confers salt and drought tolerance in rice by preventing membrane lipid peroxidation. Plant Physiol. 165, 688-704. doi: 10.1104/pp.113.230268

Campo, S., Peris-Peris, C., Montesinos, L., Peñas, G., Messeguer, J., and San Segundo, B. (2012). Expression of the maize ZmGF14-6 gene in rice confers tolerance to drought stress while enhancing susceptibility to pathogen infection. J. Exp. Bot. 63, 983-999. doi: 10.1093/jxb/err328

Capell, T., Bassie, L., and Christou, P. (2004). Modulation of the polyamine biosynthetic pathway in transgenic rice confers tolerance to drought stress. Proc. Natl. Acad. Sci. U.S.A. 101, 9909-9914. doi: 10.1073/pnas.0306974101

Chae, M.-J., Lee, J.-S., Nam, M.-H., Cho, K., Hong, J.-Y., Yi, S.-A., et al. (2007). A rice dehydration-inducible SNF1-related protein kinase 2 phosphorylates an abscisic acid responsive element-binding factor and associates with ABA signaling. Plant Mol. Biol. 63, 151-169. doi: 10.1007/s11103-006-9079-x

Chen, H., Chen, W., Zhou, J., He, H., Chen, L., Chen, H., et al. (2012). Basic leucine zipper transcription factor OsbZIP16 positively regulates drought resistance in rice. Plant Sci. 193-194, 8-17. doi: 10.1016/j.plantsci.2012.05.003

Chen, J.-Q., Meng, X.-P., Zhang, Y., Xia, M., and Wang, X.-P. (2008). Overexpression of OsDREB genes lead to enhanced drought tolerance in rice. Biotechnol. Lett. 30, 2191-2198. doi: 10.1007/s10529-008-9811-5

Chen, L.-J., Wuriyanghan, H., Zhang, Y.-Q., Duan, K.-X., Chen, H.-W., Li, Q.-T., et al. (2013). An S-domain receptor-like kinase, OsSIK2, confers abiotic stress tolerance and delays dark-induced leaf senescence in rice. Plant Physiol. 163, 1752-1765. doi: 10.1104/pp.113.224881

Chinnusamy, V., Ohta, M., Kanrar, S., Lee, B.-H., Hong, X., Agarwal, M., et al. (2003). ICE1: a regulator of cold-induced transcriptome and freezing tolerance in Arabidopsis. Genes Dev. 17, 1043-1054. doi: 10.1101/gad.1077503

Chinnusamy, V., Zhu, J., and Zhu, J.-K. (2007). Cold stress regulation of gene expression in plants. Trends Plant Sci. 12, 444-451. doi: 10.1016/j.tplants.2007. 07.002

Claeys, H., and Inzé, D. (2013). The agony of choice: how plants balance growth and survival under water-limiting conditions. Plant Physiol. 162, 1768-1779. doi: 10.1104/pp.113.220921

Cui, M., Zhang, W., Zhang, Q., Xu, Z., Zhu, Z., Duan, F., et al. (2011). Induced overexpression of the transcription factor OsDREB2A improves drought tolerance in rice. Plant Physiol. Biochem. 49, 1384-1391. doi: 10.1016/j.plaphy.2011.09.012

Cutler, S. R., Rodriguez, P. L., Finkelstein, R. R., and Abrams, S. R. (2010). Abscisic acid: emergence of a core signaling network. Annu. Rev. Plant Biol. 61, 651-679. doi: 10.1146/annurev-arplant-042809-112122

Dahl, R., Wani, B., and Hayman, M. J. (1998). The Ski oncoprotein interacts with Skip, the human homolog of Drosophila Bx42. Oncogene 16, 1579-1586. doi: 10.1038/sj.onc. 1201687

Datta, K., Baisakh, N., Ganguly, M., Krishnan, S., Yamaguchi Shinozaki, K., and Datta, S. K. (2012). Overexpression of Arabidopsis and rice stress 
genes' inducible transcription factor confers drought and salinity tolerance to rice. Plant Biotechnol. J. 10, 579-586. doi: 10.1111/j.1467-7652.2012. 00688.x

Degenkolbe, T., Do, P. T., Kopka, J., Zuther, E., Hincha, D. K., and Köhl, K. I. (2013). Identification of drought tolerance markers in a diverse population of rice cultivars by expression and metabolite profiling. PLOS ONE 8:e63637. doi: 10.1371/journal.pone.0063637

Degenkolbe, T., Do, P. T., Zuther, E., Repsilber, D., Walther, D., Hincha, D. K. et al. (2009). Expression profiling of rice cultivars differing in their tolerance to long-term drought stress. Plant Mol. Biol. 69, 133-153. doi: 10.1007/s11103-0089412-7

Deinlein, U., Stephan, A. B., Horie, T., Luo, W., Xu, G., and Schroeder, J. I. (2014). Plant salt-tolerance mechanisms. Trends Plant Sci. 19, 371-379. doi: 10.1016/j.tplants.2014.02.001

Doherty, C. J., Van Buskirk, H. A., Myers, S. J., and Thomashow, M. F. (2009). Roles for Arabidopsis CAMTA transcription factors in cold-regulated gene expression and freezing tolerance. Plant Cell 21, 972-984. doi: 10.1105/tpc.108. 063958

Dong, C.-H., Agarwal, M., Zhang, Y., Xie, Q., and Zhu, J.-K. (2006). The negative regulator of plant cold responses, HOS1, is a RING E3 ligase that mediates the ubiquitination and degradation of ICE1. Proc. Natl. Acad. Sci. U.S.A. 103, 82818286. doi: 10.1073/pnas.0602874103

Dong, M. A., Farré, E. M., and Thomashow, M. F. (2011). Circadian clock-associated 1 and late elongated hypocotyl regulate expression of the C-repeat binding factor (CBF) pathway in Arabidopsis. Proc. Natl. Acad. Sci. U.S.A. 108, 7241-7246. doi: 10.1073/pnas.1103741108

Du, H., Wang, N., Cui, F., Li, X., Xiao, J., and Xiong, L. (2010). Characterization of the beta-carotene hydroxylase gene DSM2 conferring drought and oxidative stress resistance by increasing xanthophylls and abscisic acid synthesis in rice. Plant Physiol. 154, 1304-1318. doi: 10.1104/pp.110.163741

Duan, J., and Cai, W. (2012). OsLEA3-2, an abiotic stress induced gene of rice plays a key role in salt and drought tolerance. PLOS ONE 7:e45117. doi: 10.1371/journal.pone.0045117

Duan, J., Zhang, M., Zhang, H., Xiong, H., Liu, P., Ali, J., et al. (2012). OsMIOX a myo-inositol oxygenase gene, improves drought tolerance through scavenging of reactive oxygen species in rice (Oryza sativa L.). Plant Sci. 196, 143-151. doi: 10.1016/j.plantsci.2012.08.003

Dubouzet, J. G., Sakuma, Y., Ito, Y., Kasuga, M., Dubouzet, E. G., Miura, S., et al. (2003). OsDREB genes in rice, Oryza sativa L., encode transcription activators that function in drought-, high-salt- , and cold-responsive gene expression. Plant J. 33, 751-763. doi: 10.1046/j.1365-313X.2003.01661.x

Figueroa, J. D., and Hayman, M. J. (2004). Differential effects of the Ski-interacting protein (SKIP) on differentiation induced by transforming growth factor-betal and bone morphogenetic protein-2 in C2C12 cells. Exp. Cell Res. 296, 163-172. doi: 10.1016/j.yexcr.2004.01.025

Fukao, T., and Xiong, L. (2013). Genetic mechanisms conferring adaptation to submergence and drought in rice: simple or complex? Curr. Opin. Plant Biol. 16, 196-204. doi: 10.1016/j.pbi.2013.02.003

Gao, T., Wu, Y., Zhang, Y., Liu, L., Ning, Y., Wang, D., et al. (2011). OsSDIR1 overexpression greatly improves drought tolerance in transgenic rice. Plant Mol. Biol. 76, 145-156. doi: 10.1007/s11103-011-9775-z

Golldack, D., Li, C., Mohan, H., and Probst, N. (2014). Tolerance to drought and salt stress in plants: unraveling the signaling networks. Front. Plant Sci. 5:151. doi: 10.3389/fpls.2014.00151

Gollery, M., Harper, J., Cushman, J., Mittler, T., Girke, T., Zhu, J.-K., et al. (2006). What makes species unique? The contribution of proteins with obscure features. Genome Biol. 7, R57. doi: 10.1186/gb-2006-7-7-r57

Grelet, J., Benamar, A., Teyssier, E., Avelange-Macherel, M.-H., Grunwald, D., and Macherel, D. (2005). Identification in pea seed mitochondria of a lateembryogenesis abundant protein able to protect enzymes from drying. Plant Physiol. 137, 157-167. doi: 10.1104/pp.104.052480

Guo, C., Ge, X., and Ma, H. (2013). The rice OsDIL gene plays a role in drought tolerance at vegetative and reproductive stages. Plant Mol. Biol. 82, 239-253. doi: 10.1007/s11103-013-0057-9

Hanin, M., Brini, F., Ebel, C., Toda, Y., Takeda, S., and Masmoudi, K. (2011). Plant dehydrins and stress tolerance: versatile proteins for complex mechanisms. Plant Signal. Behav. 6, 1503-1509. doi: 10.4161/psb.6.10. 17088
Hattori, Y., Nagai, K., Furukawa, S., Song, X.-J., Kawano, R., Sakakibara, H., et al. (2009). The ethylene response factors SNORKEL1 and SNORKEL2 allow rice to adapt to deep water. Nature 460, 1026-1030. doi: 10.1038/nature08258

He, Y., Hao, Q., Li, W., Yan, C., Yan, N., and Yin, P. (2014). Identification and characterization of ABA receptors in Oryza sativa. PLoS ONE 9:e95246. doi: 10.1371/journal.pone.0095246

Ho, S.-L., Huang, L.-F., Lu, C.-A., He, S.-L., Wang, C.-C., Yu, S.-P., et al. (2013). Sugar starvation- and GA-inducible calcium-dependent protein kinase 1 feedback regulates GA biosynthesis and activates a 14-3-3 protein to confer drought tolerance in rice seedlings. Plant Mol. Biol. 81, 347-361. doi: 10.1007/s11103-012-0006-Z

Hong, B., Tong, Z., Ma, N., Li, J., Kasuga, M., Yamaguchi-Shinozaki, K., et al. (2006). Heterologous expression of the AtDREB1A gene in chrysanthemum increases drought and salt stress tolerance. Sci. China C Life Sci. 49, 436-445. doi: 10.1007/s11427-006-2014-1

Hong, B., Uknes, S. J., and Ho, T.-H. (1988). Cloning and characterization of a cDNA encoding a mRNA rapidly induced by ABA in barley aleurone layers. Plant Mol. Biol. 11, 495-506. doi: 10.1007/BF00039030

Hong, J. Y., Chae, M. J., Lee, I. S., Lee, Y. N., Nam, M. H., Kim, D. Y., et al. (2011). Phosphorylation-mediated regulation of a rice $\mathrm{ABA}$ responsive element binding factor. Phytochemistry 72, 27-36. doi: 10.1016/j.phytochem.2010.10.005

Hou, X., Xie, K., Yao, J., Qi, Z., and Xiong, L. (2009). A homolog of human skiinteracting protein in rice positively regulates cell viability and stress tolerance. Proc. Natl. Acad. Sci. U.S.A. 106, 6410-6415. doi: 10.1073/pnas.0901940106

Hsieh, T. H., Lee, J. T., Charng, Y. Y., and Chan, M. T. (2002). Tomato plants ectopically expressing Arabidopsis cbf1 show enhanced resistance to water deficit stress. Plant Physiol. 130, 618-626. doi: 10.1104/pp.006783

Hu, H., Dai, M., Yao, J., Xiao, B., Li, X., Zhang, Q., et al. (2006). Overexpressing a NAM, ATAF, and CUC (NAC) transcription factor enhances drought resistance and salt tolerance in rice. Proc. Natl. Acad. Sci. U.S.A. 103, 12987-12992. doi: 10.1073/pnas.0604882103

Hu, H., You, J., Fang, Y., Zhu, X., Qi, Z., and Xiong, L. (2008). Characterization of transcription factor gene SNAC2 conferring cold and salt tolerance in rice. Plant Mol. Biol. 67, 169-181. doi: 10.1007/s11103-008-9309-5

Hua, J. (2009). From freezing to scorching, transcriptional responses to temperature variations in plants. Curr. Opin. Plant Biol. 12, 568-573. doi: 10.1016/j.pbi.2009.07.012

Huang, J., Sun, S., Xu, D., Lan, H., Sun, H., Wang, Z., et al. (2012). A TFIIIA-type zinc finger protein confers multiple abiotic stress tolerances in transgenic rice (Oryza sativa L.). Plant Mol. Biol. 80, 337-350. doi: 10.1007/s11103-012-9955-5

Huang, J., Sun, S.-J., Xu, D.-Q., Yang, X., Bao, Y.-M., Wang, Z.-F., et al. (2009). Increased tolerance of rice to cold, drought and oxidative stresses mediated by the over expression of a gene that encodes the zinc finger protein ZFP245. Biochem. Biophys. Res. Commun. 389, 556-561. doi: 10.1016/j.bbrc.2009. 09.032

Ishizaki, T., Maruyama, K., Obara, M., Fukutani, A., Yamaguchi-Shinozaki, K., Ito, Y., et al. (2012). Expression of Arabidopsis DREB1C improves survival, growth, and yield of upland New Rice for Africa (NERICA) under drought. Mol. Breed. 31, 255-264. doi: 10.1007/s11032-012-9785-9

Ito, Y., Katsura, K., Maruyama, K., Taji, T., Kobayashi, M., Seki, M., et al. (2006) Functional analysis of rice DREB1/CBF-type transcription factors involved in cold-responsive gene expression in transgenic rice. Plant Cell Physiol. 47, 141-153. doi: $10.1093 / \mathrm{pcp} / \mathrm{pci} 230$

Iuchi, S., Kobayashi, M., Taji, T., Naramoto, M., Seki, M., Kato, T., et al. (2001) Regulation of drought tolerance by gene manipulation of 9-cis-epoxycarotenoid dioxygenase, a key enzyme in abscisic acid biosynthesis in Arabidopsis. Plant J. 27, 325-333. doi: 10.1046/j.1365-313x.2001.01096.x

Jeong, J. S., Kim, Y. S., Baek, K. H., Jung, H., Ha, S.-H., Do Choi, Y., et al. (2010). Root-specific expression of OsNAC10 improves drought tolerance and grain yield in rice under field drought conditions. Plant Physiol. 153, 185-197. doi: 10.1104/pp.110.154773

Jeong, J. S., Kim, Y. S., Redillas, M. C. F. R., Jang, G., Jung, H., Bang, S. W., et al. (2013) OsNAC5 over expression enlarges root diameter in rice plants leading to enhanced drought tolerance and increased grain yield in the field. Plant Biotechnol. J. 11, 101-114. doi: 10.1111/pbi.12011

Jiang, S.-Y., Bhalla, R., Ramamoorthy, R., Luan, H.-F., Venkatesh, P. N., Cai, M., et al. (2012). Over-expression of OSRIP18 increases drought and salt tolerance in transgenic rice plants. Transgenic Res. 21, 785-795. doi: 10.1007/s11248-0119568-9 
Joo, J., Choi, H. J., Lee, Y. H., Kim, Y.-K., and Song, S. I. (2013). A transcriptional repressor of the ERF family confers drought tolerance to rice and regulates genes preferentially located on chromosome 11. Planta 238, 155-170. doi: 10.1007/s00425-013-1880-6

Kang, J., Choi, H., Im, M., and Kim, S. Y. (2002). Arabidopsis basic leucine zipper proteins that mediate stress-responsive abscisic acid signaling. Plant Cell 14, 343357. doi: $10.1105 /$ tpc.010362.tase

Karaba, A., Dixit, S., Greco, R., Aharoni, A., Trijatmiko, K. R., Marsch-Martinez, N., et al. (2007). Improvement of water use efficiency in rice by expression of HARDY, an Arabidopsis drought and salt tolerance gene. Proc. Natl. Acad. Sci. U.S.A. 104, 15270-15275. doi: 10.1073/pnas.0707294104

Kasuga, K., Liu, Q., Miura, S., Yamaguchi-Shinozaki, K., and Shinozaki, K. (1999). Improving plant drought, salt, and freezing tolerance by gene transfer of a single stress-inducible transcription factor. Nat. Biotechnol. 17, 287-291. doi $10.1038 / 7036$

Kasuga, M., Miura, S., Shinozaki, K., and Yamaguchi-Shinozaki, K. (2004). A combination of the Arabidopsis DREB1A gene and stress-inducible rd29A promoter improved drought- and low-temperature stress tolerance in tobacco by gene transfer. Plant Cell Physiol. 45, 346-350. doi: 10.1093/pcp/pch037

Kidokoro, S., Maruyama, K., Nakashima, K., Imura, Y., Narusaka, Y., Shinwari, Z. K., et al. (2009). The phytochrome-interacting factor PIF7 negatively regulates DREB1 expression under circadian control in Arabidopsis. Plant Physiol. 151, 2046-2057. doi: 10.1104/pp.109.147033

Kim, H., Lee, K., Hwang, H., Bhatnagar, N., Kim, D.-Y., Yoon, I. S., et al. (2014). Over expression of PYL5 in rice enhances drought tolerance, inhibits growth, and modulates gene expression. J. Exp. Bot. 65, 453-464. doi: 10.1093/jxb/ert397

Kim, J.-S., Mizoi, J., Kidokoro, S., Maruyama, K., Nakajima, J., Nakashima, K., et al. (2012a). Arabidopsis growth-regulating factor7 functions as a transcriptional repressor of abscisic acid- and osmotic stress-responsive genes, including DREB2A. Plant Cell 24, 3393-3405. doi: 10.1105/tpc.112.100933

Kim, H., Hwang, H., Hong, J.-W., Lee, Y.-N., Ahn, I. P., Yoon, I. S., et al. (2012b). A rice orthologue of the ABA receptor, OsPYL/RCAR5, is a positive regulator of the ABA signal transduction pathway in seed germination and early seedling growth. J. Exp. Bot. 63, 1013-1024. doi: 10.1093/jxb/err338

Koag, M.-C., Fenton, R. D., Wilkens, S., and Close, T. J. (2003). The binding of maize DHN1 to lipid vesicles. Gain of structure and lipid specificity. Plant Physiol. 131, 309-316. doi: 10.1104/pp.011171

Kuromori, T., Sugimoto, E., and Shinozaki, K. (2014). Intertissue signal transfer of abscisic acid from vascular cells to guard cells. Plant Physiol. 164, 1587-1592. doi 10.1104/pp.114.235556

Lenka, S. K., Katiyar, A., Chinnusamy, V., and Bansal, K. C. (2011). Comparative analysis of drought-responsive transcriptome in Indica rice genotypes with contrasting drought tolerance. Plant Biotechnol. J. 9, 315-327. doi: $10.1111 / j .1467-7652.2010 .00560 . x$

Li, H.-W., Zang, B.-S., Deng, X.-W., and Wang, X.-P. (2011). Over expression of the trehalose-6-phosphate synthase gene OsTPS1 enhances abiotic stress tolerance in rice. Planta 234, 1007-1018. doi: 10.1007/s00425-011-1458-0

Liu, C., Mao, B., Ou, S., Wang, W., Liu, L., Wu, Y., et al. (2014). OsbZIP71, a bZIP transcription factor, confers salinity, and drought tolerance in rice. Plant Mol. Biol. 84, 19-36. doi: 10.1007/s11103-013-0115-3

Manavalan, L. P., Chen, X., Clarke, J., Salmeron, J., and Nguyen, H. T. (2012). RNAimediated disruption of squalene synthase improves drought tolerance and yield in rice. J. Exp. Bot. 63, 163-175. doi: 10.1093/jxb/err258

Maruyama, K., Todaka, D., Mizoi, J., Yoshida, T., Kidokoro, S., Matsukura, S., et al. (2012). Identification of cis-acting promoter elements in cold- and dehydrationinduced transcriptional pathways in Arabidopsis, rice, and soybean. DNA Res. 19, 37-49. doi: 10.1093/dnares/dsr040

Maruyama, K., Urano, K., Yoshiwara, K., Morishita, Y., Sakurai, N., Suzuki, H., et al. (2014). Integrated analysis of the effects of cold and dehydration on rice metabolites, phytohormones, and gene transcripts. Plant Physiol. 164, 1759-1771. doi: 10.1104/pp.113.231720

Matsukura, S., Mizoi, J., Yoshida, T., Todaka, D., Ito, Y., Maruyama, K., et al. (2010). Comprehensive analysis of rice DREB2-type genes that encode transcription factors involved in the expression of abiotic stress-responsive genes. Mol. Genet Genomics 283, 185-196. doi: 10.1007/s00438-009-0506-y

Medina, J., Catalá, R., and Salinas, J. (2011). The CBFs: three Arabidopsis transcription factors to cold acclimate. Plant Sci. 180, 3-11. doi 10.1016/j.plantsci.2010.06.019
Michelena, V. A., and Boyer, J. S. (1982). Complete turgor maintenance at low water potentials in the elongating region of maize leaves. Plant Physiol. 69, 1145-1149. doi: 10.1104/pp.69.5.1145

Mittler, R., and Blumwald, E. (2010). Genetic engineering for modern agriculture: challenges and perspectives. Annu. Rev. Plant Biol. 61, 443-462. doi: 10.1146/annurev-arplant-042809-112116

Miura, K., Jin, J. B., Lee, J., Yoo, C. Y., Stirm, V., Miura, T., et al. (2007). SIZ1mediated sumoylation of ICE1 controls CBF3/DREB1A expression and freezing tolerance in Arabidopsis. Plant Cell 19, 1403-1414. doi: 10.1105/tpc.106.048397

Miyakawa, T., Fujita, Y., Yamaguchi-Shinozaki, K., and Tanokura, M. (2013). Structure and function of abscisic acid receptors. Trends Plant Sci. 18, 259-266. doi: $10.1016 /$ j.tplants.2012.11.002

Mizoi, J., Shinozaki, K., and Yamaguchi-Shinozaki, K. (2012). AP2/ERF family transcription factors in plant abiotic stress responses. Biochim. Biophys. Acta 1819, 86-96. doi: 10.1016/j.bbagrm.2011.08.004

Morimoto, K., Mizoi, J., Qin, F., Kim, J.-S., Sato, H., Osakabe, Y., et al. (2013). Stabilization of Arabidopsis DREB2A is required but not sufficient for the induction of target genes under conditions of stress. PLoS ONE 8:e80457. doi: 10.1371/journal.pone.0080457

Nakamura, J., Yuasa, T., Huong, T. T., Harano, K., Tanaka, S., Iwata, T., et al. (2011) Rice homologs of inducer of $C B F$ expression (OsICE) are involved in cold acclimation. Plant Biotechnol. 28, 303-309. doi: 10.5511/plantbiotechnology.11.0421a

Nakashima, K., Takasaki, H., Mizoi, J., Shinozaki, K., and Yamaguchi-Shinozaki, K. (2012). NAC transcription factors in plant abiotic stress responses. Biochim. Biophys. Acta 1819, 97-103. doi: 10.1016/j.bbagrm.2011.10.005

Nakashima, K., Tran, L.-S. P., Van Nguyen, D., Fujita, M., Maruyama, K., Todaka, D., et al. (2007). Functional analysis of a NAC-type transcription factor OsNAC6 involved in abiotic and biotic stress-responsive gene expression in rice. Plant $J$. 51, 617-630. doi: 10.1111/j.1365-313X.2007.03168.x

Nijhawan, A., Jain, M., Tyagi, A. K., and Khurana, J. P. (2008). Genomic survey and gene expression analysis of the basic leucine zipper transcription factor family in rice. Plant Physiol. 146, 333-350. doi: 10.1104/pp.107.112821

Nuruzzaman, M., Sharoni, A. M., and Kikuchi, S. (2013). Roles of NAC transcription factors in the regulation of biotic and abiotic stress responses in plants. Front. Microbiol. 4:248. doi: 10.3389/fmicb.2013.00248

Ogawa, D., Abe, K., Miyao, A., Kojima, M., Sakakibara, H., Mizutani, M., et al. (2011). RSS1 regulates the cell cycle and maintains meristematic activity under stress conditions in rice. Nat. Commun. 2, 278. doi: 10.1038/ncomms1279

Oh, S.-J., Kim, Y. S., Kwon, C.-W., Park, H. K., Jeong, J. S., and Kim, J.-K. (2009). Overexpression of the transcription factor AP37 in rice improves grain yield under drought conditions. Plant Physiol. 150, 1368-1379. doi: 10.1104/pp.109. 137554

Oh, S.-J., Kwon, C.-W., Choi, D.-W., Song, S. I., and Kim, J.-K. (2007). Expression of barley HvCBF4 enhances tolerance to abiotic stress in transgenic rice. Plant Biotechnol. J. 5, 646-656. doi: 10.1111/j.1467-7652.2007.00272.x

Oh, S., Song, S. I., Kim, Y. S., Jang, H., Kim, S. Y., Kim, M., et al. (2005). Arabidopsis CBF3 / DREB1A and ABF3 in transgenic rice increased tolerance to abiotic stress without stunting growth. Plant Physiol. 138, 341-351. doi: 10.1104/pp.104.059147.1

Ouyang, S.-Q., Liu, Y.-F., Liu, P., Lei, G., He, S.-J., Ma, B., et al. (2010). Receptor-like kinase OsSIK1 improves drought and salt stress tolerance in rice (Oryza sativa) plants. Plant J. 62, 316-329. doi: 10.1111/j.1365-313X.2010.04146.x

Parent, B., Suard, B., Serraj, R., and Tardieu, F. (2010). Rice leaf growth and water potential are resilient to evaporative demand and soil water deficit once the effects of root system are neutralized. Plant Cell Environ. 33, 1256-1267. doi: 10.1111/j.1365-3040.2010.02145.x

Park, H. C., Kim, H., Koo, S. C., Park, H. J., Cheong, M. S., Hong, H., et al. (2010). Functional characterization of the SIZ/PIAS-type SUMO E3 ligases, OsSIZ1 and OsSIZ2 in rice. Plant Cell Environ. 33, 1923-1934. doi: 10.1111/j.1365-3040.2010.02195.x

Peleg, Z., Reguera, M., Tumimbang, E., Walia, H., and Blumwald, E. (2011). Cytokinin-mediated source/sink modifications improve drought tolerance and increase grain yield in rice under water-stress. Plant Biotechnol. J. 9, 747-758. doi: 10.1111/j.1467-7652.2010.00584.x

Pellegrineschi, A., Reynolds, M., Pacheco, M., Brito, R. M., Almeraya, R., Yamaguchi-shinozaki, K., etal. (2004). Stress-induced expression in wheat of the Arabidopsis thaliana DREB1A gene delays water stress symptoms under greenhouse conditions. Genome 47, 493-500. doi: 10.1139/G03-140 
Peremarti, A., Bassie, L., Christou, P., and Capell, T. (2009). Spermine facilitates recovery from drought but does not confer drought tolerance in transgenic rice plants expressing Datura stramonium S-adenosylmethionine decarboxylase. Plant Mol. Biol. 70, 253-264. doi: 10.1007/s11103-009-9470-5

Polizel, A. M., Medri, M. E., Nakashima, K., Yamanaka, N., Farias, J. R. B., de Oliveira, M. C. N., et al. (2011). Molecular, anatomical, and physiological properties of a genetically modified soybean line transformed with rd29A: AtDREB1A for the improvement of drought tolerance. Genet. Mol. Res. 10, 3641-3656. doi: 10.4238/2011.October.21.4

Qin, F., Sakuma, Y., Tran, L.-S. P., Maruyama, K., Kidokoro, S., Fujita, Y., et al (2008). Arabidopsis DREB2A-interacting proteins function as RING E3 ligases and negatively regulate plant drought stress-responsive gene expression. Plant Cell 20, 1693-1707. doi: 10.1105/tpc.107.057380

Qin, F., Shinozaki, K., and Yamaguchi-Shinozaki, K. (2011). Achievements and challenges in understanding plant abiotic stress responses and tolerance. Plant Cell Physiol. 52, 1569-1582. doi: 10.1093/pcp/pcr106

Quan, R., Hu, S., Zhang, Z., Zhang, H., Zhang, Z., and Huang, R. (2010). Overexpression of an ERF transcription factor TSRF1 improves rice drought tolerance. Plant Biotechnol. J. 8, 476-488. doi: 10.1111/j.1467-7652.2009.00492.x

Raghavendra, A. S., Gonugunta, V. K., Christmann, A., and Grill, E. (2010). ABA perception and signalling. Trends Plant Sci. 15, 395-401. doi: 10.1016/j.tplants.2010.04.006

Ray, S., Dansana, P. K., Giri, J., Deveshwar, P., Arora, R., Agarwal, P., et al. (2011). Modulation of transcription factor and metabolic pathway genes in response to water-deficit stress in rice. Funct. Integr. Genomics 11, 157-178. doi: 10.1007/s10142-010-0187-y

Redillas, M. C. F. R., Jeong, J. S., Kim, Y. S., Jung, H., Bang, S. W., Choi, Y. D., et al. (2012). The overexpression of OsNAC9 alters the root architecture of rice plants enhancing drought resistance and grain yield under field conditions. Plant Biotechnol. J. 10, 792-805. doi: 10.1111/j.1467-7652.2012.00697.x

Rivero, R. M., Kojima, M., Gepstein, A., Sakakibara, H., Mittler, R., Gepstein, S., et al. (2007). Delayed leaf senescence induces extreme drought tolerance in a flowering plant. Proc. Natl. Acad. Sci. U.S.A. 104, 19631-19636. doi: 10.1073/pnas.0709453104

Rivero, R. M., Shulaev, V., and Blumwald, E. (2009). Cytokinin-dependent photorespiration and the protection of photosynthesis during water deficit. Plant Physiol. 150, 1530-1540. doi: 10.1104/pp.109.139378

Saijo, Y., Hata, S., Kyozuka, J., Shimamoto, K., and Izui, K. (2000). Over-expression of a single Ca2+-dependent protein kinase confers both cold and salt/drought tolerance on rice plants. Plant J. 23, 319-327. doi: 10.1046/j.1365-313x.2000.00787.x

Sakuma, Y., Maruyama, K., Osakabe, Y., Qin, F., Seki, M., and Shinozaki, K. (2006a). Functional analysis of an Arabidopsis transcription factor, dreb2a involved in drought-responsive gene expression. Plant Cell 18, 1292-1309. doi: 10.1105/tpc.105.035881.1

Sakuma, Y., Maruyama, K., Qin, F., Osakabe, Y., Shinozaki, K., and YamaguchiShinozaki, K. (2006b). Dual function of an Arabidopsis transcription factor DREB2A in water-stress-responsive and heat-stress-responsive gene expression. Proc. Natl. Acad. Sci. U.S.A. 103, 18822-18827. doi: 10.1073/pnas.0605 639103

Seo, J.-S., Joo, J., Kim, M.-J., Kim, Y.-K., Nahm, B. H., Song, S. I., et al. (2011). OsbHLH148, a basic helix-loop-helix protein, interacts with OsJAZ proteins in a jasmonate signaling pathway leading to drought tolerance in rice. Plant J. 65, 907-921. doi: 10.1111/j.1365-313X.2010.04477.x

Sharma, R., De Vleesschauwer, D., Sharma, M. K., and Ronald, P. C. (2013). Recent advances in dissecting stress-regulatory crosstalk in rice. Mol. Plant 6, 250-260. doi: $10.1093 / \mathrm{mp} / \mathrm{sss} 147$

Shen, H., Liu, C., Zhang, Y., Meng, X., Zhou, X., Chu, C., et al. (2012). OsWRKY30 is activated by MAP kinases to confer drought tolerance in rice. Plant Mol. Biol. 80, 241-253. doi: 10.1007/s11103-012-9941-y

Shu, L., Lou, Q., Ma, C., Ding, W., Zhou, J., Wu, J., et al. (2011). Genetic, proteomic and metabolic analysis of the regulation of energy storage in rice seedlings in response to drought. Proteomics 11, 4122-4138. doi: 10.1002/pmic.201 000485

Singh, A. K., Choudhury, B. U., and Bouman, B. A. M. (2002). "Water-wise rice production," in Proceedings of the international workshop on water-wise rice production, eds B. A. M. Bouman, H. Hengsdijk, B. Hardy, P. S. Bindraban, T. P. Tuong, and J. K. Ladha (Los Baños, Philippines: International Rice Research Institute), 237-248.
Skirycz, A., De Bodt, S., Obata, T., De Clercq, I., Claeys, H., De Rycke, R., etal. (2010). Developmental stage specificity and the role of mitochondrial metabolism in the response of Arabidopsis leaves to prolonged mild osmotic stress. Plant Physiol. 152, 226-244. doi: 10.1104/pp.109. 148965

Song, S.-Y., Chen, Y., Chen, J., Dai, X.-Y., and Zhang, W.-H. (2011). Physiological mechanisms underlying OsNAC5-dependent tolerance of rice plants to abiotic stress. Planta 234, 331-345. doi: 10.1007/s00425-011-1403-2

Sun, L., Zhang, Q., Wu, J., Zhang, L., Jiao, X., Zhang, S., et al. (2014). Two rice authentic histidine phosphotransfer proteins, osahp1 and osahp2, mediate cytokinin signaling, and stress responses in rice. Plant Physiol. 165, 335-345. doi: $10.1104 /$ pp. 113.232629

Swire-Clark, G. A., and Marcotte, W. R. (1999). The wheat LEA protein Em functions as an osmoprotective molecule in Saccharomyces cerevisiae. Plant Mol. Biol. 39, 117-128. doi: 10.1023/A:1006106906345

Takahashi, T., and Kakehi, J.-I. (2010). Polyamines: ubiquitous polycations with unique roles in growth and stress responses. Ann. Bot. 105, 1-6. doi: $10.1093 / \mathrm{aob} / \mathrm{mcp} 259$

Takasaki, H., Maruyama, K., Kidokoro, S., Ito, Y., Fujita, Y., Shinozaki, K., et al. (2010). The abiotic stress-responsive NAC-type transcription factor OsNAC5 regulates stress-inducible genes and stress tolerance in rice. Mol. Genet. Genomics 284, 173-183. doi: 10.1007/s00438-010-0557-0

Tang, N., Zhang, H., Li, X., Xiao, J., and Xiong, L. (2012). Constitutive activation of transcription factor OsbZIP46 improves drought tolerance in rice. Plant Physiol. 158, 1755-1768. doi: 10.1104/pp.111.190389

Tansley, T. R., and Shechter, I. (2001). Squalene synthase: structure and regulation. Prog. Nucleic Acid Res. Mol. Biol. 65, 157-195. doi: 10.1016/S00796603(00)65005-5

Thomashow, M. F. (2010). Molecular basis of plant cold acclimation: insights gained from studying the CBF cold response pathway. Plant Physiol. 154, 571-577. doi: 10.1104/pp.110.161794

Todaka, D., Nakashima, K., Maruyama, K., Kidokoro, S., Osakabe, Y., Ito, Y., et al. (2012). Rice phytochrome-interacting factor-like protein OsPIL1 functions as a key regulator of internode elongation and induces a morphological response to drought stress. Proc. Natl. Acad. Sci. U.S.A. 109, 15947-15952. doi: 10.1073/pnas.1207324109

Tuteja, N., Sahoo, R. K., Garg, B., and Tuteja, R. (2013). OsSUV3 dual helicase functions in salinity stress tolerance by maintaining photosynthesis and antioxidant machinery in rice (Oryza sativa L. cv. IR64). Plant J. 76, 115-127. doi: $10.1111 /$ tpj.12277

Uga, Y., Sugimoto, K., Ogawa, S., Rane, J., Ishitani, M., Hara, N., et al. (2013). Control of root system architecture by DEEPER ROOTING 1 increases rice yield under drought conditions. Nat. Genet. 45, 1097-1102. doi: 10.1038/ ng. 2725

Umezawa, T., Nakashima, K., Miyakawa, T., Kuromori, T., Tanokura, M., Shinozaki, K., et al. (2010). Molecular basis of the core regulatory network in ABA responses: sensing, signaling and transport. Plant Cell Physiol. 51, 1821-1839. doi: $10.1093 / \mathrm{pcp} / \mathrm{pcq} 156$

USDA. (2014). Crop Production 2013 Summary. Chesterfield, MO: National Statistics for Corn.

Voesenek, L. A. C. J., and Bailey-Serres, J. (2013). Flooding tolerance: O2 sensing and survival strategies. Curr. Opin. Plant Biol. 16, 647-653. doi: 10.1016/j.pbi.2013.06.008

Wan, L., Zhang, J., Zhang, H., Zhang, Z., Quan, R., Zhou, S., et al. (2011). Transcriptional activation of OsDERF1 in OsERF3 and OsAP2-39 negatively modulates ethylene synthesis and drought tolerance in rice. PLoS ONE 6:e25216. doi: 10.1371/journal.pone.0025216

Wang, D., Pan, Y., Zhao, X., Zhu, L., Fu, B., and Li, Z. (2011a). Genome-wide temporal-spatial gene expression profiling of drought responsiveness in rice. $B M C$ Genomics 12:149. doi: 10.1186/1471-2164-12-149

Wang, F.-Z., Wang, Q.-B., Kwon, S.-Y., Kwak, S.-S., and Su, W.-A. (2005). Enhanced drought tolerance of transgenic rice plants expressing a pea manganese superoxide dismutase. J. Plant Physiol. 162, 465-472. doi: 10.1016/j.jplph.2004. 09.009

Wang, Q., Guan, Y., Wu, Y., Chen, H., Chen, F., and Chu, C. (2008). Overexpression of a rice OsDREB1F gene increases salt, drought, and low temperature tolerance in both Arabidopsis and rice. Plant Mol. Biol. 67, 589-602. doi: 10.1007/s11103008-9340-6 
Wang, Q., Zhang, W., Yin, Z., and Wen, C.-K. (2013). Rice CONSTITUTIVE TRIPLE-RESPONSE2 is involved in the ethylene-receptor signalling and regulation of various aspects of rice growth and development. J. Exp. Bot. 64, 4863-4875. doi: $10.1093 / \mathrm{jxb} / \mathrm{ert} 272$

Wang, W.-S., Pan, Y.-J., Zhao, X.-Q., Dwivedi, D., Zhu, L.-H., Ali, J., et al (2011b). Drought-induced site-specific DNA methylation and its association with drought tolerance in rice (Oryza sativa L.). J. Exp. Bot. 62, 1951-1960. doi: 10.1093/jxb/erq391

Wei, Z., Laby, R. J., Zumoff, C. H., Bauer, D. W., He, S. Y., Colimer, A., et al. (1992). Harpin, elicitor of the hypersensitive response produced by the plant pathogen Erwinia Amylovora. Sci. 257, 85-88. doi: 10.1126/science.1621099

Weiner, J. J., Peterson, F. C., Volkman, B. F., and Cutler, S. R. (2010). Structural and functional insights into core ABA signaling. Curr. Opin. Plant Biol. 13, 495-502. doi: 10.1016/j.pbi.2010.09.007

Wolkers, W. F., McCready, S., Brandt, W. F., Lindsey, G. G., and Hoekstra, F. A. (2001). Isolation and characterization of a D-7 LEA protein from pollen that stabilizes glasses in vitro. Biochim. Biophys. Acta 1544, 196-206. doi 10.1016/S0167-4838(00)00220-X

Xiang, Y., Huang, Y., and Xiong, L. (2007). Characterization of stress-responsive CIPK genes in rice for stress tolerance improvement. Plant Physiol. 144, 14161428. doi: 10.1104/pp.107.101295

Xiang, Y., Tang, N., Du, H., Ye, H., and Xiong, L. (2008). Characterization of OsbZIP23 as a key player of the basic leucine zipper transcription factor family for conferring abscisic acid sensitivity and salinity and drought tolerance in rice. Plant Physiol. 148, 1938-1952. doi: 10.1104/pp.108.128199

Xiao, B.-Z., Chen, X., Xiang, C.-B., Tang, N., Zhang, Q.-F., and Xiong, L.-Z. (2009). Evaluation of seven function-known candidate genes for their effects on improving drought resistance of transgenic rice under field conditions. Mol. Plant 2, 73-83. doi: 10.1093/mp/ssn068

Xiao, B., Huang, Y., Tang, N., and Xiong, L. (2007). Over-expression of a LEA gene in rice improves drought resistance under the field conditions. Theor. Appl. Genet. 115, 35-46. doi: 10.1007/s00122-007-0538-9

Xu, D., Duan, X., Wang, B., Hong, B., Ho, T. D., and Wu, R. (1996). Expression of a late embryogenesis abundant protein cene, HVA7, from barley confers tolerance to water deficit and salt stress in transgenic rice. Plant Physiol. 110, 249-257.

Xu, D.-Q., Huang, J., Guo, S.-Q., Yang, X., Bao, Y.-M., Tang, H.-J., et al. (2008). Overexpression of a TFIIIA-type zinc finger protein gene ZFP252 enhances drought and salt tolerance in rice (Oryza sativa L.). FEBS Lett. 582, 1037-1043. doi: 10.1016/j.febslet.2008.02.052

Xu, M., Li, L., Fan, Y., Wan, J., and Wang, L. (2011). ZmCBF3 over expression improves tolerance to abiotic stress in transgenic rice (Oryza sativa) without yield penalty. Plant Cell Rep. 30, 1949-1957. doi: 10.1007/s00299-011-1103-1

Yamaguchi-Shinozaki, K., and Shinozaki, K. (2006). Transcriptional regulatory networks in cellular responses and tolerance to dehydration and cold stresses. Annu. Rev. Plant Biol. 57, 781-803. doi: 10.1146/annurev.arplant.57.032905.105444

Yang, A., Dai, X., and Zhang, W.-H. (2012). A R2R3-type MYB gene, OsMYB2, is involved in salt, cold, and dehydration tolerance in rice. J. Exp. Bot. 63, 2541-2556. doi: 10.1093/jxb/err431

Yang, D. H., Kwak, K. J., Kim, M. K., Park, S. J., Yang, K.-Y., and Kang, H. (2014). Expression of Arabidopsis glycine-rich RNA-binding protein AtGRP2 or AtGRP7 improves grain yield of rice (Oryza sativa) under drought stress conditions. Plant Sci. 214, 106-112. doi: 10.1016/j.plantsci.2013.10.006

Yoshida, T., Mogami, J., and Yamaguchi-Shinozaki, K. (2014). ABA-dependent and ABA-independent signaling in response to osmotic stress in plants. Curr. Opin. Plant Biol. 21, 133-139. doi: 10.1016/j.pbi.2014.07.009

Yoshida, T., Ohama, N., Nakajima, J., Kidokoro, S., Mizoi, J., Nakashima, K., et al. (2011). Arabidopsis HsfAl transcription factors function as the main positive regulators in heat shock-responsive gene expression. Mol. Genet. Genomics 286, 321-332. doi: 10.1007/s00438-011-0647-7
You, J., Hu, H., and Xiong, L. (2012). An ornithine $\delta$-aminotransferase gene OsOAT confers drought and oxidative stress tolerance in rice. Plant Sci. 197, 59-69. doi: 10.1016/j.plantsci.2012.09.002

Yu, H., Chen, X., Hong, Y.-Y., Wang, Y., Xu, P., Ke, S.-D., et al. (2008). Activated expression of an Arabidopsis HD-START protein confers drought tolerance with improved root system and reduced stomatal density. Plant Cell 20, 1134-1151. doi: 10.1105/tpc.108.058263

Yu, L., Chen, X., Wang, Z., Wang, S., Wang, Y., Zhu, Q., et al. (2013). Arabidopsis enhanced drought tolerance1/HOMEODOMAIN GLABROUS11 confers drought tolerance in transgenic rice without yield penalty. Plant Physiol. 162, 1378-1391. doi: 10.1104/pp.113.217596

Zhang, H., Liu, W., Wan, L., Li, F., Dai, L., Li, D., et al. (2010). Functional analyses of ethylene response factor JERF3 with the aim of improving tolerance to drought and osmotic stress in transgenic rice. Transgenic Res. 19, 809-818. doi: 10.1007/s11248-009-9357-x

Zhang, H., Zhang, J., Quan, R., Pan, X., Wan, L., and Huang, R. (2013). EAR motif mutation of rice OsERF3 alters the regulation of ethylene biosynthesis and drought tolerance. Planta 237, 1443-1451. doi: 10.1007/s00425-013-1852-x

Zhang, L., Xiao, S., Li, W., Feng, W., Li, J., Wu, Z., et al. (2011). Overexpression of a Harpin-encoding gene hrf1 in rice enhances drought tolerance. J. Exp. Bot. 62, 4229-4238. doi: 10.1093/jxb/err131

Zhang, Q., Li, J., Zhang, W., Yan, S., Wang, R., Zhao, J., et al. (2012). The putative auxin efflux carrier OsPIN3t is involved in the drought stress response and drought tolerance. Plant J. 72, 805-816. doi: 10.1111/j.1365-313X.2012.05121.x

Zhao, J., Ren, W., Zhi, D., Wang, L., and Xia, G. (2007). Arabidopsis DREB1A/CBF3 bestowed transgenic tall fescue increased tolerance to drought stress. Plant Cell Rep. 26, 1521-1528. doi: 10.1007/s00299-007-0362-3

Zhao, Y., Ma, Q., Jin, X., Peng, X., Liu, J., Deng, L., et al. (2014). A novel maize homeodomain-leucine zipper (HD-Zip) I gene, Zmhdz10, positively regulates drought, and salt tolerance in both rice and Arabidopsis. Plant Cell Physiol. 55, 1142-1156. doi: 10.1093/pcp/pcu054

Zhu, J.-K. (2002). Salt and drought stress signal transduction in plants. Annu. Rev. Plant Biol. 53, 247-273. doi: 10.1146/annurev.arplant.53.091401.143 329

Zong, W., Zhong, X., You, J., and Xiong, L. (2013). Genome-wide profiling of histone $\mathrm{H} 3 \mathrm{~K} 4$-tri-methylation and gene expression in rice under drought stress. Plant Mol. Biol. 81, 175-188. doi: 10.1007/s11103-012-9990-2

Zou, J., Liu, C., Liu, A., Zou, D., and Chen, X. (2012). Over expression of OsHsp17.0 and OsHsp23.7 enhances drought and salt tolerance in rice. J. Plant Physiol. 169, 628-635. doi: 10.1016/j.jplph.2011.12.014

Conflict of Interest Statement: The authors declare that the research was conducted in the absence of any commercial or financial relationships that could be construed as a potential conflict of interest.

Received: 08 October 2014; paper pending published: 09 January 2015; accepted: 02 February 2015; published online: 18 February 2015.

Citation: Todaka D, Shinozaki K and Yamaguchi-Shinozaki K (2015) Recent advances in the dissection of drought-stress regulatory networks and strategies for development of drought-tolerant transgenic rice plants. Front. Plant Sci. 6:84. doi: 10.3389/fpls.2015.00084

This article was submitted to Plant Biotechnology, a section of the journal Frontiers in Plant Science.

Copyright (C) 2015 Todaka, Shinozaki and Yamaguchi-Shinozaki. This is an openaccess article distributed under the terms of the Creative Commons Attribution License (CC BY). The use, distribution or reproduction in other forums is permitted, provided the original author(s) or licensor are credited and that the original publication in this journal is cited, in accordance with accepted academic practice. No use, distribution or reproduction is permitted which does not comply with these terms. 